\title{
Adolescent Girls Initiative-Kenya: Midline results report
}

\author{
Karen Austrian \\ Population Council \\ Erica Soler-Hampejsek \\ Joyce Mumah \\ Beth Kangwana \\ Population Council \\ Yohannes Dibaba Wado
}

See next page for additional authors

Follow this and additional works at: https://knowledgecommons.popcouncil.org/departments_sbsr-pgy

Part of the International Public Health Commons, and the Social and Behavioral Sciences Commons How does access to this work benefit you? Let us know!

\section{Recommended Citation}

Austrian, Karen, Erica Soler-Hampejsek, Joyce Mumah, Beth Kangwana, Yohannes Dibaba Wado, Benta Abuya, Valsa Shah, and John A. Maluccio. 2018. "Adolescent Girls Initiative-Kenya: Midline results report." Nairobi: Population Council. 


\section{Authors}

Karen Austrian, Erica Soler-Hampejsek, Joyce Mumah, Beth Kangwana, Yohannes Dibaba Wado, Benta Abuya, Valsa Shah, and John A. Maluccio 


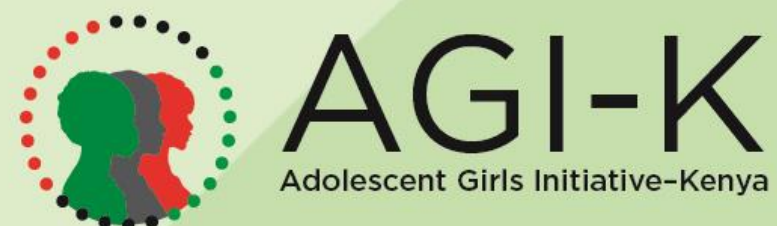

\section{Adolescent Girls Initiative-Kenya MIDLINE RESULTS REPORT}

JULY 2018 


\section{POPULATION COUNCIL}

Ideas. Evidence. Impact.

The Population Council confronts critical health and development issues-from stopping the spread of HIV to improving reproductive health and ensuring that young people lead full and productive lives. Through biomedical, social science, and public health research in 50 countries, we work with our partners to deliver solutions that lead to more effective policies, programs, and technologies that improve lives around the world. Established in 1952 and headquartered in New York, the Council is a nongovernmental, nonprofit organization governed by an international board of trustees.

Population Council

Avenue 5, 3rd Floor

Rose Avenue

PO Box 17643-00500

Nairobi

Kenya

Tel: +254202713480

Tel2: +254202713481

Fax: +254202713479

www.popcouncil.org

\section{AUTHORS}

Karen Austrian, PhD, MPH

Senior Associate

Population Council, Kenya

kaustrian@popcouncil.org

Erica Soler-Hampejsek, PhD

Independent Consultant

Spain

Beth Kangwana, PhD

Senior Program Officer

Population Council, Kenya
Joyce Mumah, PhD

Associate Research Scientist APHRC

Yohannes Dibaba Wado, PhD

Post-Doctoral Research

Scientist

APHRC

Benta A. Abuya, PhD

Research Scientist

APHRC

\section{Valsa Shah \\ Senior Consultant Itad}

John Maluccio, PhD

Professor of Economics Middlebury College

Suggested citation: Austrian, K., Soler-Hampejsek, E., Mumah, J., Kangwana, B., Wado, Y., Abuya, B., Shah, V. and Maluccio, J. 2018. “Adolescent Girls Initiative-Kenya: Midline Results Report.” Nairobi: Population Council.

Prepared July 2018. This is a technical paper and represents research in progress. This paper represents the opinions of the authors and is the product of professional research. This paper has not been peer reviewed, and this version may be updated with additional analyses in subsequent publications. 


\section{Contents}

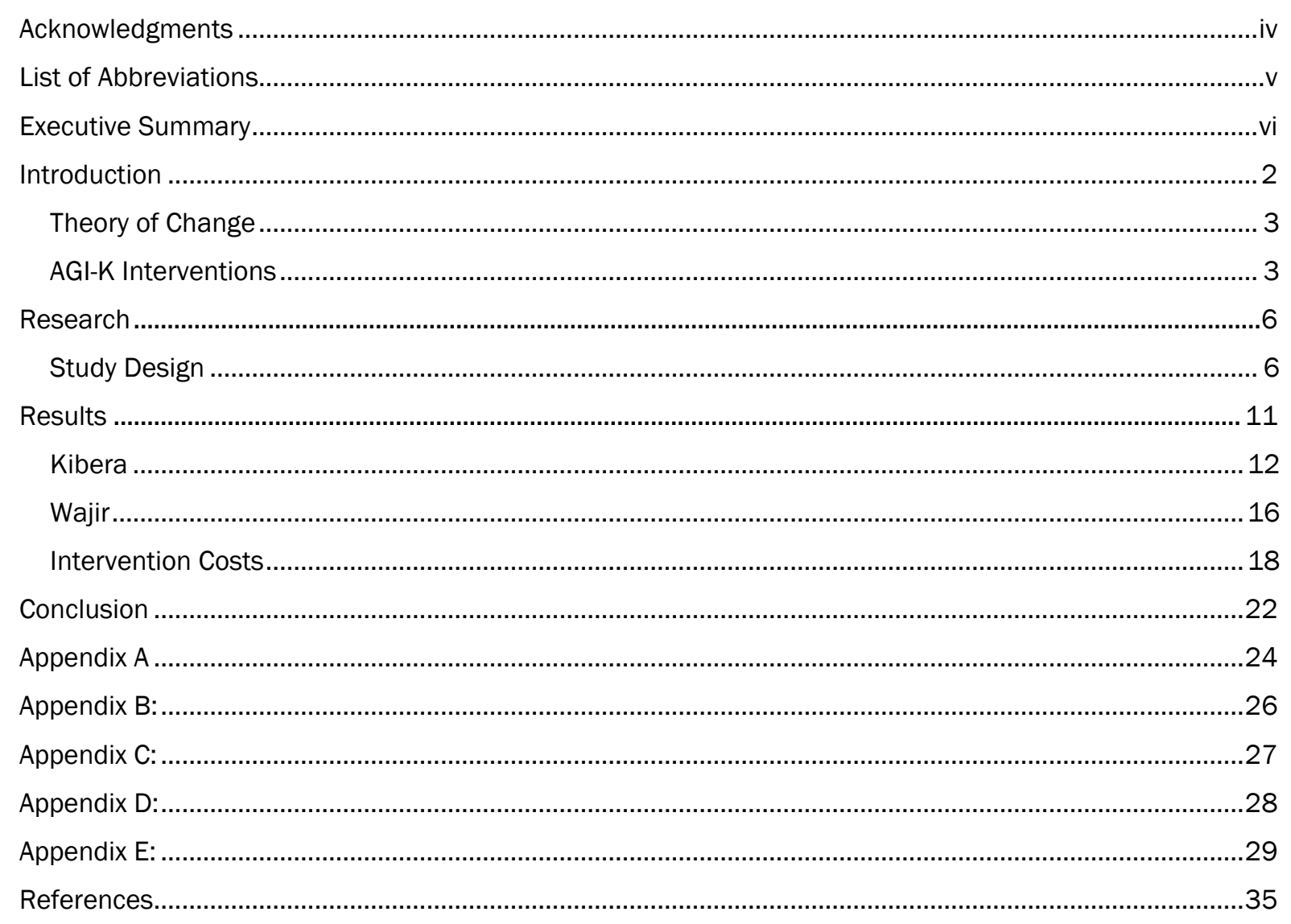




\section{Acknowledgments}

The AGI-K midline report would not be possible without the hard work of the project partners and research teams dedicated to improving the lives of vulnerable adolescent girls. AGI-K is implemented by a consortium led by the Population Council, with the African Population and Health Research Centre (APHRC) as a research partner, Save the Children as implementing partner in Wajir, Plan International as implementing partner in Kibera, and Itad as consultant on the cost-effectiveness analysis. We would like to thank all of the project members as well as the members of the AGI-K National External Advisory Committee (EAC) and the Kibera and Wajir EACs for their invaluable input into the interpretation of the midline results (see Appendix A).

We would like to acknowledge the efforts of the large team of dedicated research assistants and supervisors who collected the data, with the midline led by Vivian Njoki in Kibera and James Serembe in Wajir. The entire exercise was coordinated by AGI-K Study Coordinators Eva Muluve and Faith Mbushi, with logistical support by Philisters Obunga, based in the Population Council office in Kenya. We are also grateful for the contributions of Eunice Muthengi to the inception and implementation of the study while she was a staff member at Population Council. We similarly thank Caroline Kabiru, formerly of APHRC, for contributions in the early phases of the study. We thank Charles Gatama for programming the tools using Open Data Kit for electronic data capture and Lilian Nduku for coordinating the biomarker data collection. We also thank Population Council's AGI-K Program Coordinator, Diana Moreka, and Program Managers Joyce Kimani and Evans Kibet of Save the Children and Joy Koech of Plan International, for overall management and oversight of intervention activities.

The authors thank the UK Department for International Development (DFID) for investing in rigorous research that will provide evidence to influence national policy and will support scaled-up, cost-effective interventions for adolescent girls in the future. We also thank those from DFID-Kenya and the AGI-K Expert Research Committee who provided feedback on drafts of this report.

Finally, we are grateful to the adolescent girls and their parents/guardians who participated in the research and took the time to share their thoughts and experiences with us. 


\title{
List of Abbreviations
}

\author{
AGI-K - Adolescent Girls Initiative-Kenya \\ AMREF - African Medical and Research Foundation \\ APHRC - African Population and Health Research Center \\ CAPI - Computer-Assisted Personal Interviewing \\ CCT - Conditional Cash Transfer \\ DAC - Development Assistance Committee \\ DFID - Department for International Development \\ DID - Difference in Difference \\ EAC - External Advisory Committee \\ FE - Financial Education \\ FGM/C - Female Genital Mutilation/Cutting \\ HIV - Human Immunodeficiency Virus \\ HSV-2 - Herpes Simplex Virus Type 2 \\ IPV - Inactive Polio Vaccine \\ IRB - Institutional Review Board \\ ITT - Intent-to-Treat \\ IV - Instrumental Variable \\ KCPE - Kenya Certificate for Primary Examination \\ KDHS - Kenya Demographic and Health Survey \\ KES - Kenya Shillings \\ KNBS - Kenya National Bureau of Statistics \\ M\&E - Monitoring and Evaluation \\ MIS - Management Information Systems \\ ODK - Open Data Kit \\ PCA - Principal Component Analysis \\ PSM - Propensity Score Matching \\ RCT - Randomized Controlled Trial \\ SRH - Sexual and Reproductive Health \\ STI - Sexually Transmitted Infection \\ TOT - Treatment-on-the-Treated
}




\section{Executive Summary}

\section{INTRODUCTION}

Many adolescent girls in Kenya face considerable risks and vulnerabilities that affect their education status, health, and general well-being. In addition to low educational attainment and health risks - including early marriage, teenage pregnancy, early and unprotected sexual activity, nonconsensual sex, and HIV/STIS other factors that impact education and health outcomes include household poverty, lack of economic independence, limited income-earning opportunities, illiteracy, violence, and social isolation. Younger adolescent girls who live in environments laden with these vulnerabilities are at risk of experiencing negative outcomes such as school dropout, early sexual initiation, unintended pregnancy, early marriage, and sexual and gender-based violence. Therefore, it is critical to intervene before the myriad of challenges that girls face result in outcomes that are irreversible or become too costly to compensate.

The Adolescent Girls Initiative-Kenya (AGI-K) delivered multi-sectoral interventions to over 6,000 girls ages 11-15 in two marginalized areas of Kenya: 1) the Kibera informal settlement in Nairobi and 2) Wajir County in Northeastern Kenya. Implemented by Plan International in Kibera and Save the Children in Wajir, these interventions were carried out for two years and comprised a combination of girl-level, household-level, and community-level interventions. The hypothesis is that these interventions would build girl-level social, education, health, and economic assets, as well as improve household economic assets in the medium term, which will lead to delayed childbearing in the longer term.

The goal of AGI-K is unique in that it tests packages of four multi-sectoral interventions, rather than only single-sector interventions. The Violence Prevention intervention included community dialogues and action plans where a key group of adult stakeholders in each community met regularly to discuss the challenges facing girls in their area and develop and implement a plan to address at least one of those challenges. The Education intervention was a conditional cash transfer (CCT) that included a bi-monthly payment to the household, direct payment of a portion of school fees, and a schooling kit for the girls; all incentives were conditioned on girls' enrollment and regular attendance at school. The Health intervention included weekly girls' group meetings, or safe spaces, facilitated by a young woman from the community that covered a range of health and life-skills topics. The Wealth Creation intervention included financial education within the group meetings, as well as savings accounts in the urban site and home banks in the rural site.

A randomized controlled trial (RCT) was used to compare the impact of three different packages of multisectoral interventions relative to a single community-level intervention, together with their costs, to assess if and how intervening in early adolescence will impact girls' life chances. AGI-K implemented the following packages:
1) Violence Prevention (V-only)
2) Violence Prevention + Education (VE)
3) Violence Prevention + Education + Health (VEH)
4) Violence Prevention + Education + Health + Wealth Creation (VEHW/full program package)

This report briefly describes both the intervention and research design of AGI-K, and presents the impact findings from the midline data collection from Wajir County and Kibera. The overall objective of the RCT is to describe and compare the impact of the different program packages at the end of the program. Endline data will be collected in 2019 and will reflect the impact of the program packages two years postintervention. 


\section{KEY FINDINGS}

\section{Kibera}

The CCT improved the rates of primary school completion and the transition to secondary school for girls who were in the final two years of primary school at the start of the intervention. These results were largest and statistically significant for girls who received the full program package. In addition, the cash transfer improved household wealth status vis-à-vis cash liquidity and relative wealth status for all three program packages that included the education intervention.

The health intervention (weekly girls' groups) resulted in clear improvements for girls in the two program packages with the health intervention on contraception knowledge, SRH knowledge, condom self-efficacy, help-seeking self-efficacy, and social safety nets (both among age-mates and with female adults). However, the intervention did not have an effect on attitudes around the acceptability of intimate partner violence or equitable gender norms.

The wealth creation intervention had clear positive impacts on levels of financial literacy, savings frequency, and savings amount for girls in the full program package.

While the effect of the violence prevention intervention on its own was not evaluated due to the evaluation design (V-only arm served as the control), when packaged together with the other interventions, there was a positive effect in reducing girls' experience of physical, emotional, and sexual violence by males in the past year.

Important to note is that for girls who actively participated in the safe spaces (health and wealth creation), the impact not only on their health and wealth outcomes was larger, but also on their education outcomes - implying that participating in girls' groups with combined health and economic content had spillover effects onto their educational attainment.

\section{Wajir}

In Wajir, where about a quarter of girls were out of school at baseline, the education CCT had a large impact on primary school enrollment and retention. These impacts held true for all three arms receiving the education CCT. However, the CCT did not translate into increases in household economic status, suggesting that the Wajir households spent more of the transfer on daily household needs as opposed to cash and asset accumulation.

The health intervention with the health, life skills, and nutrition curriculum, did not increase knowledge for girls in the VEH and VEHW arms on contraception, menstrual health, HIV/STIs, or nutrition. For the girls in the VEHW arm there were small but positive effects on help-seeking self-efficacy. For the girls who actively participated in the VEHW arm, there was also a positive effect on general self-efficacy. There was no change in acceptability of violence. There was some positive change on equitable gender attitudes related to men's and women's roles, for example who should make decisions in a household or whether a boy's education should be prioritized over a girl's where there is a lack of resources.

The financial literacy and savings activities had a positive impact on the girls receiving the full program package in Wajir. There was a large increase in financial literacy scores and savings frequency and amount. For girls who participated actively in the girls' group meetings/safe spaces, the effect was twice as large.

It appears that violence is significantly underreported as only $3 \%$ of girls at baseline and $4 \%$ of girls at midline reported experiencing violence in the past one year. Validation meetings with local stakeholders in Wajir confirm that this is grossly underreported, likely because of significant taboos around disclosing and discussing violence. Therefore, even if the program did have an effect on the experience of violence, it is not possible to detect. However, household-level norms around expectations of girls' educational 
attainment improved for those households in the VE, VEH and VEHW arms and the percent of households that expected their daughters to marry before 18 dropped in both the VEH and VEHW arms.

\section{Education}

Overall, the effects of the conditional cash transfer were positive, but the particular area of impact was dependent on the baseline status of girls' education in each site. In Kibera, because the cash transfer was beneficial for those girls completing primary and transitioning to secondary school, moving forward, narrowing the scope of the recipients of the CCT, from girls in urban informal settlements to those nearing the transition from primary to secondary school, will be more cost-effective. In Wajir, CCT had large positive effects on bringing out-of-school girls into school and ensuring that those who are behind in their schooling relative to their age remained enrolled; this implies that future CCTs in settings such as Wajir should therefore target those segments of adolescents.

\section{Health}

In Kibera, the safe spaces groups impacted the girls as expected, improving knowledge, self-efficacy, and social safety nets. Even more promising is the positive impact of active participation in the safe spaces groups not only on health outcomes, but also on education outcomes. The results suggest that being an active part of a girl's empowerment club, which focus on improving health knowledge, self-efficacy, and social safety nets, goes on to further improve education outcomes. This makes the investment in the cost of establishing and maintaining the safe spaces platform good value for money.

In Wajir however, the health intervention (girls' groups with health content) did not have the hypothesized impact. Validation meetings with key stakeholders and implementers in Wajir suggest that despite that community sensitization, mentor training, audio training sessions, and monitoring, the community, and specifically the mentors themselves, were unwilling to deliver the sessions on sexual and reproductive health topics with girls. The objection was not with the delivery channel, as the groups met, and the economic content did have an impact, but to the SRH-focused content itself. The implication is that perhaps in very socially conservative settings with little infrastructure and economic resources, the entry into the community should be first via improvements in education, wealth creation and infrastructure. This recommendation on entry points is further reflected by the way in which action plans were prioritized by the community conversation groups. In Kibera, community conversation groups focused on creating resource centers and learning opportunities for girls, that is, activities for girls, while in Wajir, they focused on making improvements to school infrastructure. However, even despite conservative attitudes toward SRH in Wajir, there were small improvements in self-efficacy and gender norms - both at the girl and household levels. This suggests that the safe spaces groups could be a platform to positively change SRH outcomes, but the process through which the community will accept SRH-focused content to enable this to happen is longer than the AGI-K program allows.

\section{Wealth Creation}

The wealth creation intervention led to some of the largest and most consistent changes in both sites, indicating that financial education and savings for girls are both accepted and impactful. The combination of financial education sessions with savings mechanisms further supports the literature in that having the opportunity to immediately put into practice newly acquired skills helps financial literacy training to "stick." The endline survey will confirm whether the improvement in economic assets for girls will have a long-term influence on the timing and choices around marriage and sexual relationships.

The cost of layering on the wealth creation intervention to the safe spaces platform was relatively minimal, and the education effect sizes were greater in the arm that included wealth creation as compared to the arms that did not Therefore, the recommendation for future programs would be to couple the health content with financial literacy and savings opportunities. In addition, in areas where formal financial services are accessible, creating opportunities for adolescent girls to open and own their own savings accounts is important for financial institutions in Kenya to consider in order to improve savings behaviors. 


\section{Violence Prevention}

Although the study design does not allow us to evaluate the impact of the community-based intervention on its own, we still believe that it is important vis-à-vis the theory of change to work at multiple levels of a girls' ecosystem and couple household and girl-level interventions to address girls' empowerment with a community component. Addressing and understanding the enabling environment for girls is important so that girls and their families can leverage improvements in education, skills, and knowledge, which will in turn eventually translate into longer-term change. One explanation is that creating space at the community level in Wajir opened up space for the positive changes in gender norms at the household level driven by the other interventions.

\section{Cost-Effectiveness}

The conclusion from the midline results on value for money is that when the objective is to maximize girls' welfare on a range of indicators, it is more cost-effective to use a multi-sectoral approach. That is, by undertaking education interventions alongside wealth and health interventions, where implementing each intervention component costs less when packaged, a wider range of outcomes are achieved.

\section{CONCLUSIONS}

Overall the AGI-K program had positive effects on short- and medium-term education, social, health, and economic assets. The endline survey, to be conducted two years after the end of the intervention, will confirm if these changes in assets in the short-to-medium term will translate into longer term change in delaying childbearing - whether it be through delaying marriage in Wajir or delaying sexual debut and/or increasing contraceptive use in Kibera. However, given that the hypothesized midterm effects have largely been achieved, with a few exceptions in particular sectors, the potential for the AGI-K interventions to delay childbearing remains.

The evidence emerging from the AGI-K midline survey is encouraging. It has shown that positive change is possible in two very different, marginalized settings in Kenya. It reinforces the point that context matters and that the pathways to asset-building and empowerment vary in different settings. Future interventions targeting vulnerable girls need to take into account the setting and focus on specific segments of girls in order to maximize efficiency of spending resources - particularly on education-support programs. The evidence also reinforces the theory that addressing empowerment for adolescent girls through a multisectoral approach leads to larger impact and that "cash plus," or supplementing household economic incentives with additional social, health, and asset building for girls themselves, provides the best value for money when looking across education, health, and economic outcomes. 


\section{Introduction}

Many adolescent girls in Kenya face considerable risks and vulnerabilities that affect their education status, health, and general well-being. In addition to low educational attainment and health risks - including early marriage, teenage pregnancy, early and unprotected sexual activity, nonconsensual sex, and HIV/STIs other factors that impact education and health outcomes include household poverty, lack of economic independence, limited income-earning opportunities, illiteracy, violence, and social isolation. Younger adolescent girls who live in environments laden with these vulnerabilities are at risk of experiencing negative outcomes such as school dropout, early sexual initiation, unintended pregnancy, early marriage, and sexual and gender-based violence. For example, nearly one-quarter of women in Kenya have given birth by age 18 and almost half by age 20; a third of girls 15-17 years old have experienced physical or sexual violence (Kenya DHS 2013-14). Therefore, it is critical to intervene before the myriad of challenges girls face result in outcomes that are irreversible or are costly to compensate for or reverse.

The root causes of these vulnerabilities work in tandem to create the current situation for adolescent girls cultural norms that do not empower women and girls, acceptance of violence, poverty, social isolation, economic vulnerability, lack of voice in society - and therefore the interventions that will enable girls in early adolescence to make a safe and healthy transition through adolescence and into adulthood must be integrated as well. In order to achieve well-being for girls in early and late adolescence, no single-sector intervention - whether it be education, health, wealth creation, or prevention of violence - will be adequate.

The Adolescent Girls Initiative-Kenya (AGI-K) delivered multi-sectoral interventions to over 6,000 girls ages 11-15 in two marginalized areas of Kenya: 1) the Kibera informal settlement in Nairobi and 2) Wajir County in Northeastern Kenya. Implemented by Plan International in Kibera and Save the Children in Wajir, these interventions were carried out for two years and comprised a combination of girl-level, household-level, and community-level interventions. The interventions took into account the numerous complex, multifaceted, and interrelated factors that influence the well-being of very young adolescents living in varying geographies - urban and rural Kenya. The rationale for such an initiative that combines health, wealth, education, and violence prevention is that when the diverse asset base is fully realized, it will lead to increased educational attainment, fewer unintended pregnancies, less experience of violence, and increased income generation. Further, this study expands the evidence base highlighting the need for social protections programs, especially cash transfers, to move beyond 'cash only' to include the provision of other services and information so as to increase, and potentially sustain, the impacts of the income effects.

A randomized controlled trial (RCT) is used to compare the impact of three different packages of interventions relative to a single community-level intervention, together with their costs, to assess if and how intervening in early adolescence will impact girls' life chances. The overall purpose of the evaluation is to learn and add to the global body of literature on what works to improve outcomes for adolescent girls. The information here can be used by policymakers, donors, and program planners who are interested in using evidence-based program design.

This report briefly describes both the intervention and research design of AGI-K, and presents the impact findings from the midline data collection from rural areas of Wajir County and Kibera, an urban informal settlement in Nairobi. The objective is to describe and compare the impact of the different program packages at the end of the program. Endline data will be collected in 2019 and will reflect the impact of the program packages two years post-intervention.

Of the five DAC criteria, this study addresses the efficiency, effectiveness, and impact criteria via the kind of data being collected and will be able to make rigorous statements on these three points. The interventions tested were designed with relevance and sustainability also in mind, such that if the study finds a positive impact, there will be potential for scale-up of the interventions. Some elements of the study also align with the Paris Declaration in that a national-level advisory committee, made up of members of relevant government ministries, other donors, and civil society organizations, guided the design of the intervention and research. 


\section{THEORY OF CHANGE}

The interventions for AGI-K were based on the Asset Building Theory of Change that posits that girls need a combination of education, social, health, and economic assets to make a safe, healthy, and productive transition from childhood into young adulthood (Bruce and Sebstad 2004, Austrian and Ghati 2010). In addition, strengthening the household economic status and addressing community norms regarding girls' values are also critical components to turning short-term increases in assets for girls into the resulting improvements in medium- and longer-term outcomes (see Figure 1). While the overall goal is to delay childbearing, the pathways in each of the two study sites are different - by delaying sexual debut and/or increasing contraceptive use in Kibera and by delaying marriage in Wajir.

FIGURE 1. AGI-K Theory of Change

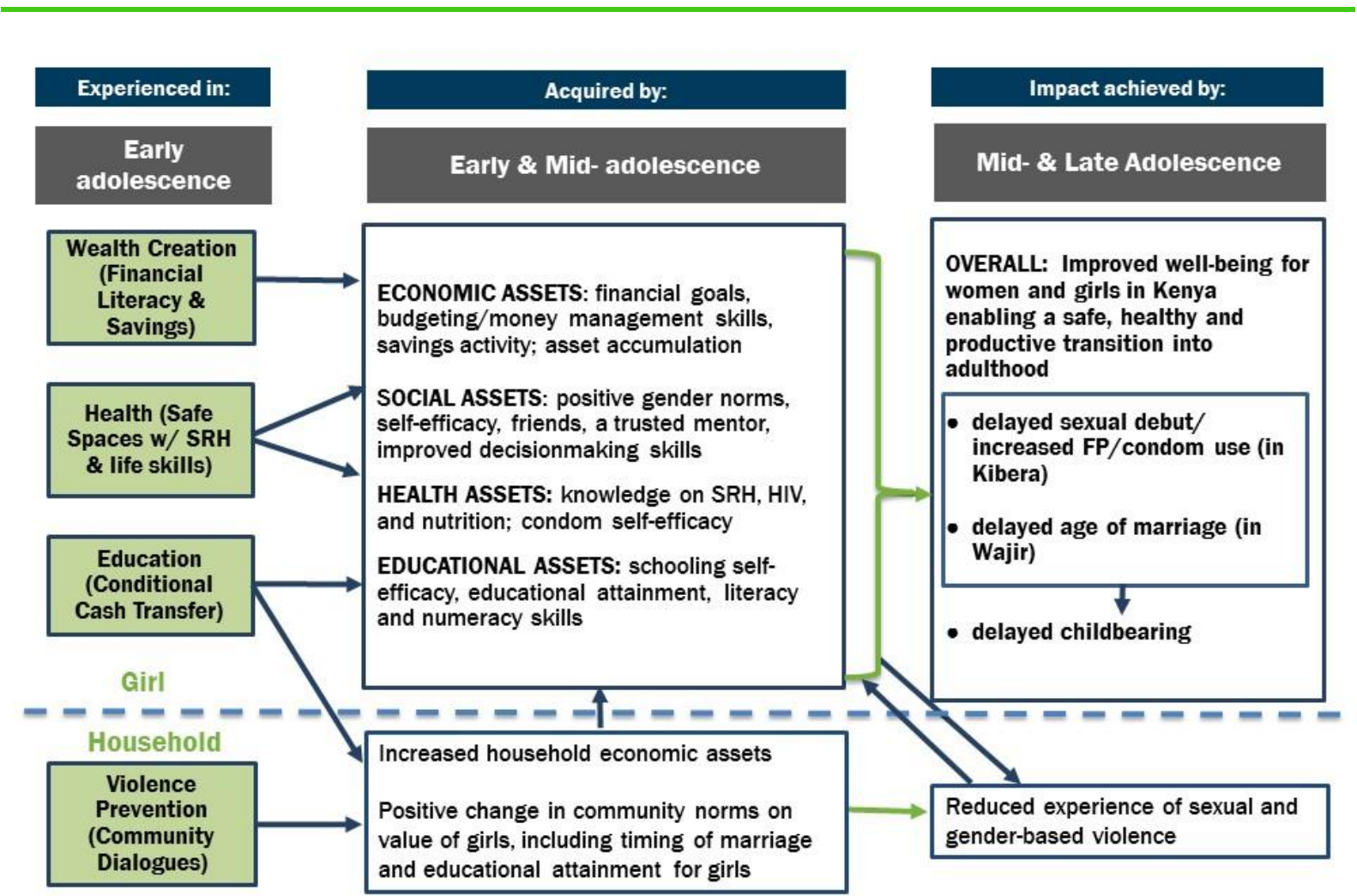

\section{AGI-K INTERVENTIONS}

As mentioned above, the goal of AGI-K is not to test single-sector interventions but to test multi-sectoral packages of interventions. AGI-K implemented the following packages:
1) Violence Prevention (V-only)
2) Violence Prevention + Education (VE)
3) Violence Prevention + Education + Health (VEH)
4) Violence Prevention + Education + Health + Wealth Creation (VEHW)

The selection of package combinations was based on three factors: 1) prioritizing what component effects were important to isolate; 2) generating evidence on new interventions and new combinations of interventions for which there are none; and 3) testing packages with varying implementation costs. The intervention design was guided by the theory of change and then each intervention component was adapted to take into account the local context. 


\section{Sector-Specific Interventions ${ }^{1}$}

\section{Violence Prevention}

The violence prevention intervention employed community-level dialogues and contracts. A committee was established in each community and included religious and community leaders, parents, teachers, and young men and women. The groups were taken through a facilitated process to identify key issues in the community that lead to the undervaluing of girls and the perpetuating of violence against girls and women. The committee then developed an action plan to implement a project meant to address and alleviate the issues facing girls in their community that they had identified. Each community conversation group was given a small fund with which to implement their project.

\section{Education}

The education intervention included a cash transfer conditioned on enrollment at the start of each term and regular attendance ${ }^{2}$ throughout the term. At the start of the intervention, all girls-whether in school or out of school-were eligible for the transfer upon school enrollment. The four components of the conditional transfer included:

1) fees, if applicable, to be paid directly to the school at the start of each term ${ }^{3}$,

2) a cash transfer paid to the head of the household twice per term ${ }^{4}$,

3) schooling kits given directly to girls at the start of each term containing sanitary towels, underpants, and basic school supplies; and

4) an incentive paid directly to the school based on the number of girls enrolled in the cash transfer program $^{5}$.

\section{Health}

The health intervention is based on the Population Council's safe spaces model (Austrian and Ghati 2010) in which girls met in groups once a week under the guidance of a female mentor from the community. Groups were segmented by age (11-12-year-olds in one group and 13-14-year-olds in the other) in Nairobi and by schooling status in Wajir. Group meetings included facilitated discussions using a health, life-skills, and nutrition curriculum, ${ }^{6}$ as well as time for open discussion. In Wajir, the sessions used pre-recorded audio sessons to address wide variation in the capacity of the mentors ${ }^{7}$.

\footnotetext{
1 For more details on the design of and rationale behind the selection of each intervention component see Adolescent Girls Initiative - Kenya: Baseline Report or Study Protocol.

2 Attendance was taken on a randomly selected day by external research assistants (RA) who visited the school and checked for the girl's presence. If a girl was absent on that day, the RA would return on a random day the following week. If a girl was absent on both days, she was deemed ineligible for the next payment.

${ }^{3}$ KES 700 ( US\$7) for primary school and KES 6000 ( US\$60) for secondary school.

4 The cash transfer payment amount in Kibera was KES 1,125 ( US\$11) and in Wajir the amount was KES 1,500 (approx. US\$15).

5 The incentive payment was KES 500 ( US\$5) per girl.

6 http://www.popcouncil.org/uploads/pdfs/2015PGY_AGI-K_HealthLifeCurriculum_Wajir.pdf http://www.popcouncil.org/uploads/pdfs/2015PGY_AGI-K_HealthLifeCurriculum_Kibera.pdf

7 http://www.popcouncil.org/uploads/pdfs/2018PGY_AGI-K_HLS-TrainingScriptWajir.pdf
} 


\section{Wealth Creation}

The wealth creation intervention included a financial education (FE) curriculum integrated into the safe spaces group meetings ${ }^{8}$. In Wajir, girls received a home bank (piggybank), and in Kibera, girls opened a girl-friendly savings account with the Kenya Post Office Savings Bank (Postbank). Girls in both sites received a small annual incentive of KES 300 ( US\$3) to allow them to put into practice the skills learned in the FE sessions.

8 http://www.popcouncil.org/uploads/pdfs/2015PGY_AGI-K_FinancialCurriculum_Wajir.pdf http://www.popcouncil.org/uploads/pdfs/2015PGY_AGI-K_FinancialCurriculum_Kibera.pdf http://www.popcouncil.org/uploads/pdfs/2018PGY_AGI-K_FE-TrainingScriptWajir.pdf 


\section{Research}

\section{STUDY DESIGN9}

The initial overall research questions for AGI-K were:

1) Which combination(s) of interventions produce(s) the greatest change in the well-being of adolescent girls?

2) What is the most cost-effective way to achieve the greatest impact for adolescent girls?

The research design for the study is a longitudinal randomized controlled trial (RCT). The unit of randomization is different for the two sites: individual-level randomization in Kibera and cluster randomization in Wajir because of the differing geographies and population clustering. Each site is treated as a sub-study. For each sub-study, selected clusters/individuals were randomly assigned to one of the four arms after a household listing and baseline data collection were completed (see Figure 2). Assignment of clusters/individuals to study arms was conducted in the form of a public lottery to increase transparency. In Nairobi, an external control was also followed, in Huruma. In Wajir, the V-only arm served as the control.

FIGURE 2. Randomized Controlled Trial Design

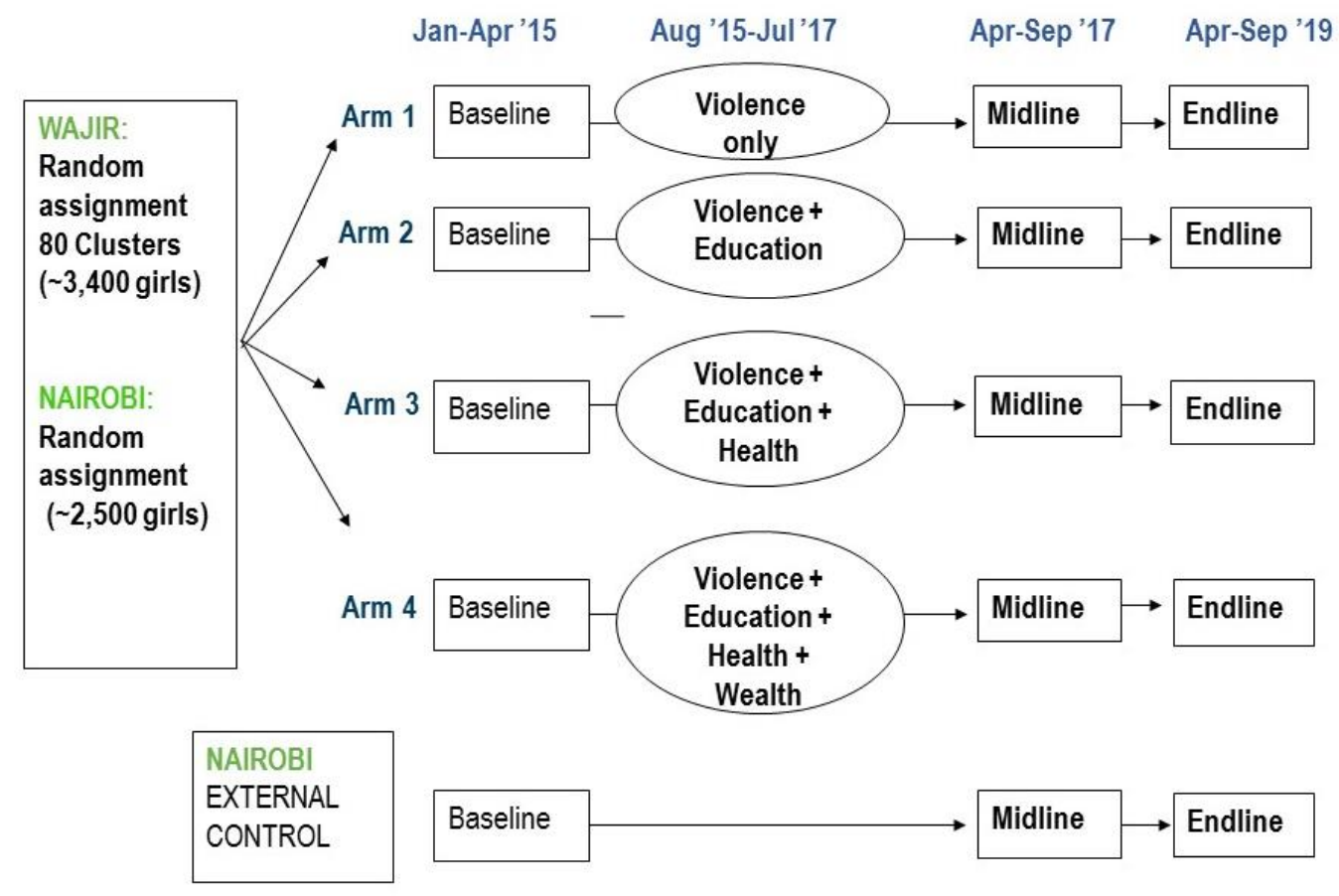

The primary target population were girls ages 11-14 who were residing within selected study sites at the time of the baseline survey and who were not in boarding school at the time of the listing and/or at the time of the survey. ${ }^{10}$ Parents, guardians, and community members within these sites were targeted within the violence-prevention intervention.

The baseline survey was conducted between February and May 2015 in both study sites. The midline survey was conducted among the same cohort interviewed at baseline between April-July 2017 in Kibera and July-September 2017 in Wajir. Female survey interviewers with at least a diploma or Bachelor's degree were recruited from each of the project locations. Supervisors with considerably more research experience were recruited to oversee interviewers, led by a study coordinator in each site. Interviewers

9 For more details on the study design see Austrian et al. 2016.

10 For Kibera, because sampling was conducted based on a listing of households over a period of several months, the age cutoffs include girls who had not yet turned 15 as of November 20, 2015, and were at least 11 years of age by January 18, 2015. 
visited each household to conduct the interview with randomly selected respondents. Before administering the survey, informed consent was obtained from parents/guardians of girls and assent from the girls themselves. Parental consent was not required from emancipated minors (e.g., married girls). To the extent possible, interviews were conducted in an area with visual and auditory privacy. If the respondent was not present at the household on the day of the interviewer's visit, the interviewer was instructed to pay at least three visits to the household in order to locate and interview the selected respondent. Interviewers also interviewed girls at school after obtaining consent from parents and school administrators. For girls who moved outside the study area between baseline and midline, teams were dispatched at midline to locate and interview them, after obtaining parental/guardian consent, at their current location of residence.

Survey instruments were implemented by electronic data capture: Computer-Assisted Personal Interviewing (CAPI) on tablet computers. CAPI is a process of data capture in which the interviewer reads the question from a computer screen and enters the participant's response directly into a handheld or tablet device.

The study was reviewed and approved for compliance by the Population Council Institutional Review Board (IRB) and the AMREF Ethics \& Scientific Review Committee. In addition, research permits were obtained from the National Council on Science, Technology and Innovation in Kenya.

\section{Research Instruments}

The quantitative survey ${ }^{11}$ covered topics such as: socio-demographic characteristics, schooling history, education attainment, social assets and networks, self-efficacy, locus-of-control, financial literacy, savings and livelihoods, marital and childbearing aspirations, birth history, experience of physical and sexual harassment and violence, attitudes on FGM/C, self-reported health and nutrition, reproductive health knowledge, HIV and AIDS risk perception, exposure to AGI-K, reading comprehension in local language and English, excerpts from official mathematics assessments multiple standards (grades), and cognitive testing. The survey was translated into Swahili and Somali, and pilot-tested and revised based on feedback from interviewers before data collection began. In addition, girls in the Kibera site ${ }^{12}$ who were 15 years and above were tested for HIV and herpes simplex virus type 2 (HSV-2) at midline. HIV results and counseling were given at the time of the testing and girls were given a voucher to return to the study office in Kibera to obtain HSV-2 results three weeks after the test.

11 Baseline and midline instruments are available for download in the Resources section of the Adolescent Girls Initiative-Kenya webpage at: http://www.popcouncil.org/research/adolescent-girls-initiative-action-research-program.

12 Given the very low prevalence of HIV/HSV-2 in Wajir, it was not useful to collect this biomarker data there. 
TABLE 1. Key Midline Indicators Per Sector

\begin{tabular}{|c|c|}
\hline \multicolumn{2}{|c|}{ Key Midline Indicators Per Sector } \\
\hline Violence Prevention & $\begin{array}{l}\text {-experience of physical, emotional or sexual } \\
\text { violence by a male in the past one year } \\
\text {-if reported experience of violence, sought help } \\
\text {-household-level norms on timing of girls, marriage } \\
\text {-household-level norms on girls, educational } \\
\text { attainment }\end{array}$ \\
\hline Education & $\begin{array}{l}\text {-primary school enrollment (Wajir only) } \\
\text {-among those in class } 7 \text { and } 8 \text { at baseline: \% who } \\
\text { completed primary school } \\
\text {-among those in class } 7 \text { and } 8 \text { at baseline: \% who } \\
\text { transitioned to secondary school } \\
\text {-literacy score } \\
\text {-numeracy score }\end{array}$ \\
\hline Health & $\begin{array}{l}\text {-contraceptive method knowledge } \\
\text {-sexual and reproductive health knowledge } \\
\text { (menstruation/STIs, HIV) } \\
\text {-general self-efficacy } \\
\text {-condom self-efficacy } \\
\text {-help-seeking self-efficacy } \\
\text {-social safety nets (trusted adults, trusted friends) }\end{array}$ \\
\hline Wealth Creation & $\begin{array}{l}\text {-financial literacy score } \\
\text {-savings frequency } \\
\text {-savings amount } \\
\text {-household liquidity } \\
\text {-household wealth status }\end{array}$ \\
\hline
\end{tabular}

A short household survey was also conducted with the head of household or adult providing consent at the time of the interview, to collect information about the household's experience of major shocks, receipt of other cash transfers, exposure to AGI-K and other programs, and gender norms.

Qualitative data was collected in 2016 and published in a separate report13 and again in April-May 2018. The qualitative work will capture the views of girls, as well as additional stakeholders such as teachers mentors, parents, and community leaders. Those data will be analyzed and published separately as the purpose of this report is to present the quantitative findings.

\section{Program-Monitoring Data}

All program data were carefully monitored and stored on a cloud-based MIS platform available to the program and research teams. Mentors collected safe spaces attendance data using Open Data Kit (ODK) on smart phones where at each meeting they recorded the date, session covered, and girls who were in attendance. 


\section{Analysis}

First, we analyzed program take-up among girls in the research sample using the program-monitoring data. We then assessed balance across study arms at baseline using Pearson chi-square tests for categorical variables and linear regression for continuous variables.

Next, to estimate the impact of the education, health, and wealth interventions, we compared each study arm with combinations of these interventions to the V-only arm, following an intent-to-treat (ITT) approach. ITT is defined as girls randomized to a specific study arm in Kibera, and as girls living in a village randomized to a specific study arm in Wajir, regardless of girls' actual participation in the interventions. We also compared the VEH arm to the VE arm and the VEHW arm to the VE arm and the VEH arm. In Nairobi, we had intended to use an external control and Propensity Score Matching (PSM) to evaluate the impact of the V-only arm, as such matching methods are common in the evaluation literature. However, analysis of trends over time between the two urban sites in Nairobi did not allow for a meaningful comparison (see Appendix E for more details). Even when difference-in-difference is possible to control for fixed effects, a crucial assumption underlying PSM is that of common trends: in the absence of the intervention, the difference between the two groups is assumed to be constant over time. In other words, the areas are not "developing" or trending in a different fashion over time for non-program related reasons. A crucial step in justifying non-experimental approaches like this, then, is to examine to the extent possible the common trends assumption. The weight of evidence from our analysis, however, is that for reasons beyond our control the common trends assumption was not valid, and the two locations were on different trajectories, and we therefore do not report estimated impacts on violence-related outcomes using the external comparison site.

For outcomes that were measured both before the start of the intervention (at baseline) and at the end of the intervention (two years after the baseline) we estimated difference-in-differences (DID) with girl-level fixed effects. For outcomes that were not measured at baseline we estimated simple differences at the end of the intervention.

We then tested whether the interventions had differential impacts for older compared to younger girls by including interaction terms with baseline age groups (age 13 and older versus age 12 and younger). We also tested whether the interventions had differential impacts for girls from the poorest backgrounds by including interaction terms with baseline wealth quintiles (poorest quintile versus all others, and poorest quintile versus wealthiest quintile).

Finally, while the majority of girls randomized to the education intervention received the education intervention components, girls randomized to the health and wealth interventions which included attendance at weekly meetings had different levels of participation and thus different exposures to the interventions. Therefore, we conducted a secondary analysis to assess the impact of the treatment-on-thetreated (TOT) for the health and wealth interventions, i.e., the program effect for those actively participating. The TOT analysis was conducted as a two-stage instrumental variable (IV) estimation. The ITT is used as the instrumental variable in the first stage to predict a certain level of participation in the weekly meetings. ${ }^{14}$ Three different levels of participation were assessed: (i) attendance at a minimum of 52 meetings (about half of the total meetings); (ii) attendance above the median attendance in the specific study site; (iii) attendance above the median attendance in the specific study arm and site.

All regressions for Kibera were estimated with robust standard errors, and all regressions for Wajir were estimated with robust standard errors accounting for clustering at the village level. All regressions were reestimated controlling for girls' age as arms were balanced at baseline on other key background indicators. All statistical analysis was conducted using Stata 15.1.

14 The strength and validity of the instrumental variable was assessed with F-tests of excluded instruments, the partial R2 of excluded instruments, and the Hansen statistic for overidentification. All equations are exactly identified, the Ftests are above 10, and the partial R2s are high (ranging from around 0.17-0.40). 


\section{Methodology for estimating cost per beneficiary}

In order to estimate the cost per beneficiary, the method chosen was to treat arm-specific costs (equipment, mentoring) slightly differently to non-arm specific costs (overheads, M\&E15). For the former, these were directly attributed to the arms themselves. For the latter, these were allocated depending on a weighting factor which ideally best reflects the level appropriate for that specific arm. Direct variable costs (i.e., arm-specific costs) were separated out from non-arm-specific costs (namely community sensitization, capacity development, M\&E, piloting, media and communication, stationary, recruitment costs, transport, security, office and staff). It was then necessary to spread the non-arm-specific costs across the arms. This was done in two ways depending on which was most accurate:

(1) using a weighting factor based on arm-specific costs; for example, if Violence Prevention comprised $28 \%$ of total arm-specific costs, a weighting factor of $28 \%$ was used to allocated nonarm-specific costs, i.e., $28 \%$ of non-arm-specific costs are allocated to Violence Prevention.

(2) The weighting percentage is estimated based on program experience from program experts. This usually gives a more true representation of the level of effort of each non-arm-specific cost category allocated across each arm.

The arm-specific and non-arm-specific costs were added together for each arm to calculate total cost per intervention. Finally, the total cost per intervention was divided by the total number of beneficiaries receiving each intervention.

\section{Limitations}

While the overall study design is quite rigorous, there are a few potential sources of bias. The first is that the baseline sample could be biased from the overall population that it is intended to represent, because of non-response at baseline. Second, there could be differential attrition between baseline and midline by arm. This potential bias was explored, and in Wajir there was no differential attrition by arm. However, in Kibera, girls in the V-only arm were more likely to be lost-to-follow-up as compared to the other three arms. Finally, there is potential bias from the selectivity of girls participating in higher numbers of safe spaces sessions, but we addressed this with the IV models.

15 The costs of the impact evaluation were excluded from the costing calculations as only the costs of an ongoing program are included. This included minimal M\&E costs incurred by the implementing partners. 


\section{Results}

This AGI-K midline survey report focuses on the impact of the intervention on key indicators in each of the four sectors: education, health, wealth creation, and violence. The results presented compare the violence prevention-only arm to the other three arms. The full set of tables are detailed in Appendix B (ITT) and C (TOT). In addition, Appendix D shows the detailed results of the interaction tests described above. The initial study design also planned for a comparison of the violence prevention-only arm in Kibera to the external control site in Huruma. However, evidence of differential trends in schooling and wealth called into question the use of matching techniques for assessing aspects of the AGI-K program using the external comparison group from Huruma. Consequently, we did not pursue this approach to examine AGI-K program effects, including the impact of the violence prevention-only arm. A brief on the propensity scorematching approach and full results are detailed in Appendix E.

Results for Kibera and Wajir are presented separately. The two locations differ greatly with respect to economic opportunities, geography, religion, and culture, so a direct comparison is not possible. However, some of the differences in impact between the two sites provide further insights into what did and did not have an effect in different contexts.

Overall midline response rates were high with $91 \%(n=2,181)$ of the Kibera baseline sample being interviewed at midline, $89 \%(n=1,912)$ of the Wajir sample, and $86 \%$ of the Huruma sample (external control). $25 \%$ of the original Kibera sample was tracked and interviewed outside of Nairobi City County. All baseline respondents, regardless of whether or not they were interviewed at midline, will be included in the endline sample.

These results will be shared with key stakeholders at sub-county, county, and national levels. Additional thematic policy briefs will be available on the study website. ${ }^{16}$

\section{Program take-up}

Overall, participation in the cash transfer was high with only $7.5 \%$ of eligible households in Kibera and $11.5 \%$ of eligible girls in Wajir never receiving a cash transfer over the two-year intervention period. The mean number of transfers received (out of a total possible of 12) was 9.5 and 9 in Kibera and Wajir, respectively. $82 \%$ of girls in the VEHW arm in Kibera opened savings accounts with Postbank ${ }^{17}$ and $79 \%$ of girls in the VEHW arm in Wajir received a homebank.

Attendance in safe spaces groups was more varied (see Table 2). If groups met each week over the course of the two years, a girl could attend approximately 100 sessions in total. In Kibera, the mean number of sessions attended was 36 and about $6 \%$ of girls in the VEH and VEHW arms never attended their safe spaces group and $48 \%$ participated in the mean or higher number of sessions. In Wajir, the mean was 33 sessions and about $8 \%$ of eligible girls never attended a session and $47 \%$ participated in the mean or higher number of sessions.

Interesting to note, in both sites, the mean number of sessions attended in the VEHW arm was 4-5 sessions higher as compared to girls in the VEH arm. When looking at the trends of safe spaces attendance, in Kibera safe spaces attendance dipped in December of each year because of the holidays, and stayed low between January-March 2017 as a) many girls had transitioned to boarding secondary schools and "caught up" on safe spaces when they returned in April and b) the pending elections in August 2017 created an unstable environment in Kibera for the first half of that year. In Wajir, while girls remained a part of their group throughout the two years, attendance dipped during school holiday months (April, August, and December) as during those times a) girls were often sent away to assist with tending livestock, b) girls traveled to visit other relatives, and c) some mentors who were teachers were not available as they also traveled during the school holiday. While the total number of sessions may seem low, the attendance trends suggest that girls remain a part of the group over the entire two years, but only

16 http://www.popcouncil.org/research/adolescent-girls-initiative-action-research-program.

17 Cash transfer payments were made into an Equity Bank account held by the girl's mother, father, or guardian. Girls

in the VEHW arm opened their own savings accounts at Postbank - irrespective of the Equity Bank accounts. 
attend once or twice per month as opposed to concentrated attendance at the start followed by a sharp drop off.

TABLE 2. Safe Spaces Participation Summary

\begin{tabular}{|l|l|l|l|l|}
\hline & VEH Mean & VEH Median* & VEHW Mean & VEHW Median* \\
\hline Kibera & 34 & 33 & 38 & 38 \\
\hline Wajir & 31 & 25 & 35 & 36 \\
\hline
\end{tabular}

*The half of the sample that attended the median or above number of sessions were included as the "active participants" for the purposes of the TOT analysis

\section{KIBERA}

Overall, estimated effects discussed refer to ITT difference-in-difference unless otherwise noted. When presenting percentages, we refer to midline levels. For indicators only measured at midline, simple differences are presented.

\section{Education}

Enrollment remained at about $98 \%$ in all arms at both baseline and midline. In terms of primary school completion, among girls who had completed Class 6 by baseline, and thus logically would be able to complete primary school (Class 8) by midline, girls in the CCT arms were more likely to have completed primary school (91\% compared to $84 \%$ ) and the effect was statistically significant for girls in the VE and VEHW arms. Girls who had completed Class 6 by baseline and were in the CCT arms were also up to almost 8 percentage points higher in the transition to secondary school as compared to girls not eligible for the CCT (89\% compared to 81\%). For both of these indicators, the effect was largest and statistically significant relative to the V-only arm for girls in the VEHW arm, although the difference between the arms was not statistically significant for these two indicators.

We observed no differences in either literacy/numeracy scores, or KCPE18 scores, between the girls who were and were not eligible for the CCT. Overall there was not a lot of change in learning outcomes between baseline and endline, suggesting that learning skills are solidified in the early grades. Since not all girls participated at the same level in the program, the actual program effects on girls who participated more intensively are likely diluted in the ITT estimates. When looking at the TOT estimates, for girls who participated in more than the mean number of safe spaces sessions for their arm, the effects on education were typically twice as large as the ITT estimates - for example, girls in the VEHW arm who actively participated in safe spaces meetings were 19 percentage points higher in the transition to secondary school and missed four fewer days of school. In the TOT estimate, the VEHW arm was also significantly higher than the VE and VEH arms for primary school completion and significantly higher than the VE arm in the transition to secondary school.

18 The KCPE is the Kenya Certificate of Primary Examination and is the test taken at the end of Class 8 which determines eligibility for entry into secondary school. 
FIGURE 3. Estimated Effects on Primary School Completion and Secondary School Enrollment - Kibera, ITT

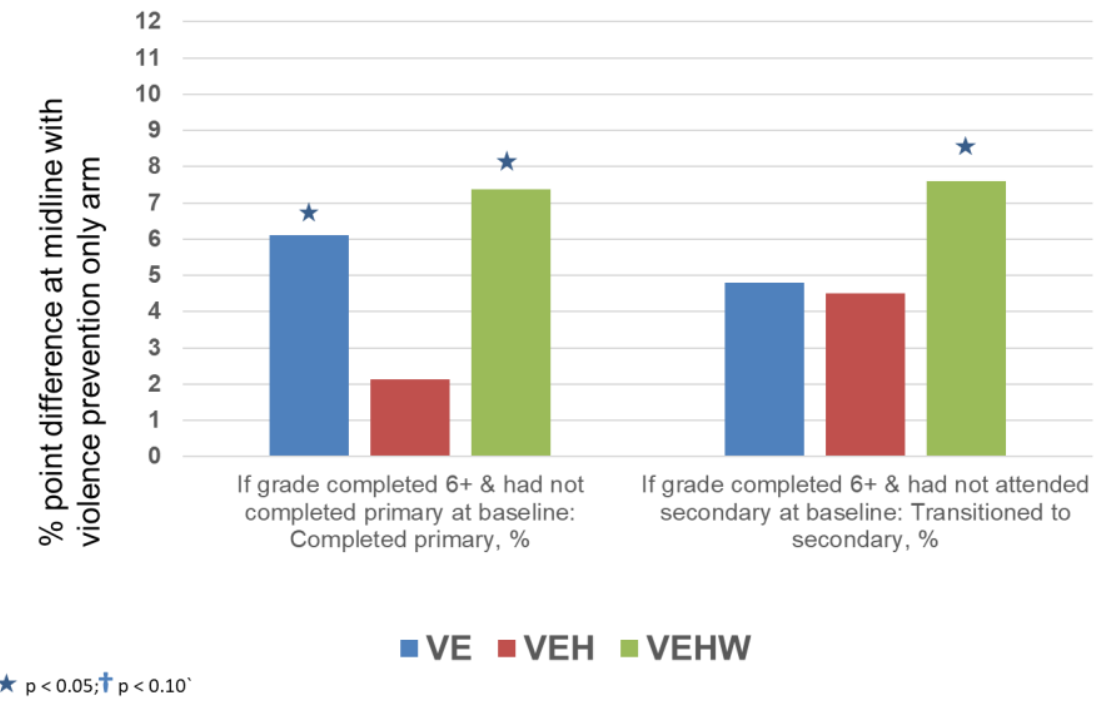

\section{Health}

The hypothesis for health outcomes was that girls who participated in safe spaces groups would have higher levels of health knowledge and other measures of social assets. Indeed, girls in the VEH and VEHW arms were statistically significantly more likely to know about modern methods of contraception, including condoms, compared to both the V-only and VE arms as just over half of the V-only and VE girls could name a method of contraception as compared to two-thirds of the VEH and VEHW girls. Girls in the VEHW arm also showed higher knowledge on menstrual health compared to the V-only and VE girls. For example, at baseline just over half of girls in all arms knew that there was a fertile period; at midline, $70 \%$ of girls in the V-only and VE arms knew about the fertile period, compared to $75 \%$ of girls in the VEH arm and $79 \%$ of girls in the VEHW arm. There were small, marginally significant increases in HIV and STI knowledge for the VEH arm compared to the V-only and VE arms. There was no effect on knowledge on nutrition.

FIGURE 4. Estimated Effects on HIV, SRH, and Nutrition Knowledge - Kibera, ITT
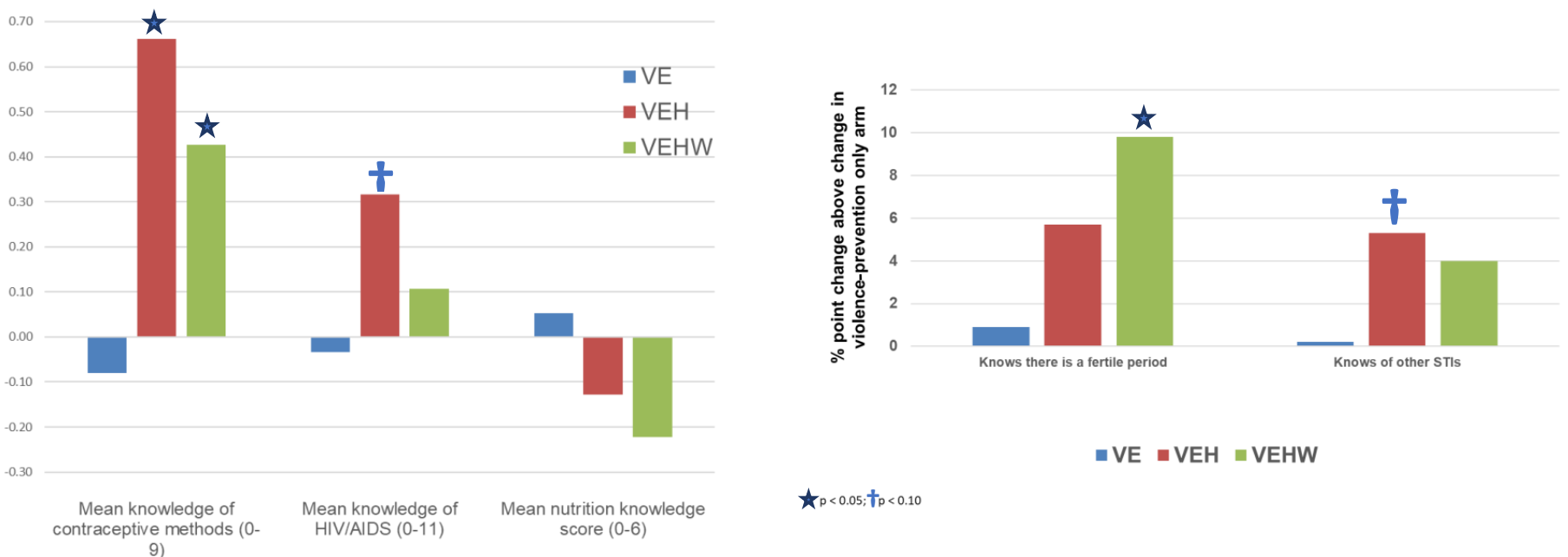

$\because \mathrm{VE} \square \mathrm{VEH}=\mathrm{VEHW}$ 
There was no effect on general self-efficacy, although the hypothetical situations posed in the battery of general self-efficacy questions proved difficult for many younger girls to understand. ${ }^{19}$ However, there were small yet statistically significant effects on condom self-efficacy ${ }^{20}$ and help-seeking self-efficacy ${ }^{21}$ for girls in the VEH and VEHW arms compared to the V-only and VE arms, and a positive effect on schooling self-efficacy 22 for girls in the VE arm (which can also be seen as an education outcome). The effects on social safety nets were clear among girls in the VEH and VEHW compared to the V-only girls on having nonmother/teacher female adults in their community that they meet regularly and can go to with a problem or a question. Girls in all three arms, relative to the V-only arm, were more likely to have female friends in the community that they meet with regularly and can go to with a problem or a question - indicating that girls were able to strengthen their peer networks both at school and in the safe spaces groups.

When looking at the TOT estimates, the effects remain the same on knowledge, self-efficacy and social safety-net indicators. However, the effect size typically doubled for girls who participated in more than the mean number of safe spaces sessions for their arm. For example, while the difference in the change between baseline and midline for the VEH and VEHW arms compared to the V-only arm on knowledge of modern methods of contraception was $12 \%$ in the ITT estimates, it was $24 \%$ in the TOT analysis. Also, when comparing the health effects for the VEH and VEHW arms relative to the VE arm, there are many more significant differences, indicating that the improvements on health and social outcomes were due to the safe spaces groups and the health content, which neither the V-only nor the VE girls received.

\section{FIGURE 5. Estimated Effects on Social Safety Nets - Kibera, ITT}

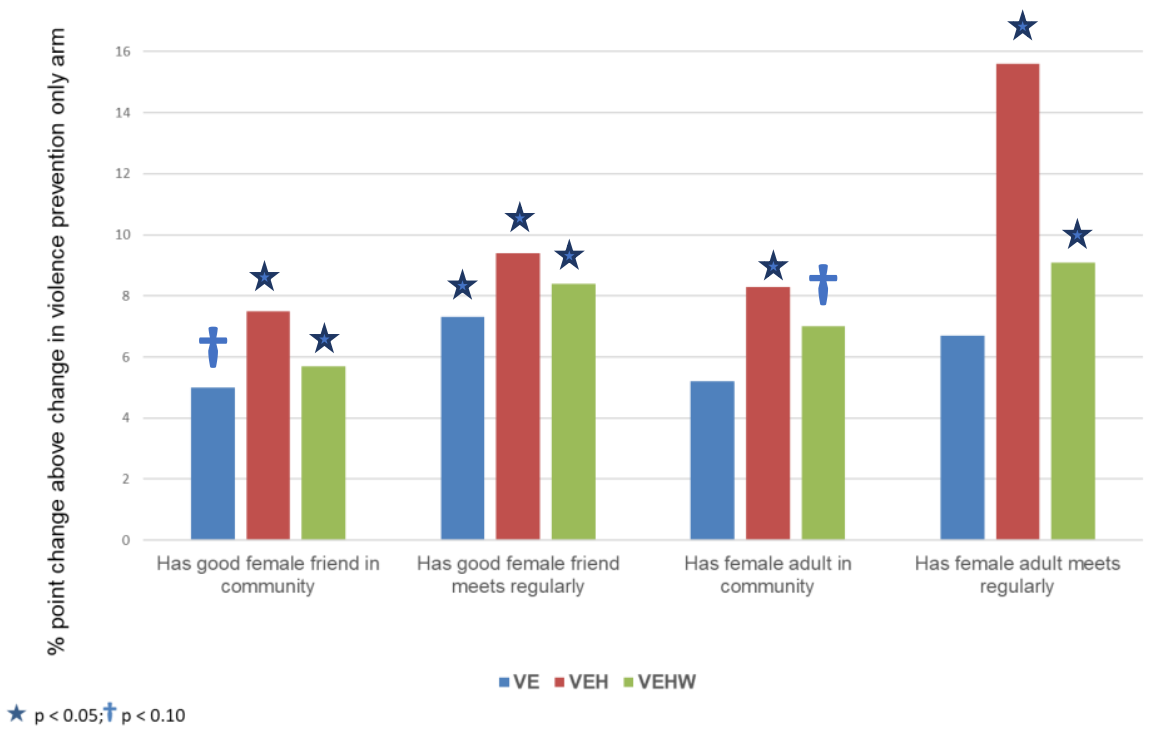

The program did not have an effect on acceptability of violence (which was relatively high at baseline with $50 \%$ of girls among all arms agreeing that a husband beating his wife was acceptable in at least one circumstance) or equitable gender norms (which was generally positive with about half of all girls among all arms ascribing to positive gender norms at baseline and almost two-thirds at midline). In addition, there was no difference between study arms on the longer-term outcomes of sexual behavior, pregnancy, and marriage. This is expected as the sample is still quite young (13-17 years old at midline) and only $6.5 \%$ of the sample reported having sex and $2 \%$ having been pregnant. Overall, $1.5 \%$ of the girls 15 and above in the sample were HIV positive and $11 \%$ tested positive for HSV-2.

19 These questions will be asked again at baseline, as well as an additional set of measures drawn from the Global Early Adolescent Study instrument that are more suitable for younger adolescents.

20 The belief in one's ability to use a condom with the skills one possesses.

21 The belief in one's ability to seek out help in situations when help is needed.

22 The belief in one's ability to achieve success in school or school-related challenges. 


\section{Wealth Creation}

For key wealth creation indicators on financial literacy and savings behavior, it was hypothesized that the wealth creation intervention would have a positive effect. When comparing scores on a financial literacy scale at the end of the two-year intervention, girls in the VEHW arm's mean financial literacy scores improved by almost one point while there was no change for the girls in the non-wealth creation arms. Girls in the VEHW arm also had greater increases in savings behavior - both frequency and amount - with an increase in having saved in the past six months, informal or formal, 20 percentage points higher than the non-wealth creation arm girls and 41 percentage points higher when looking at savings in a bank account. Girls also amassed double the amount of savings between baseline and midline compared to the $\mathrm{V}$-only girls. All of the wealth creation effects for the VEHW were statistically significantly higher than the Vonly, VE and VEH arms - that is, all those that did not receive the wealth creation intervention.

Similar to the health outcomes, for VEHW girls who participated actively in their safe spaces groups, the effect sizes relative to the violence prevention-only arm on financial literacy and savings behavior doubled.

FIGURE 6. Financial Literacy and Savings Behaviors - Kibera, ITT

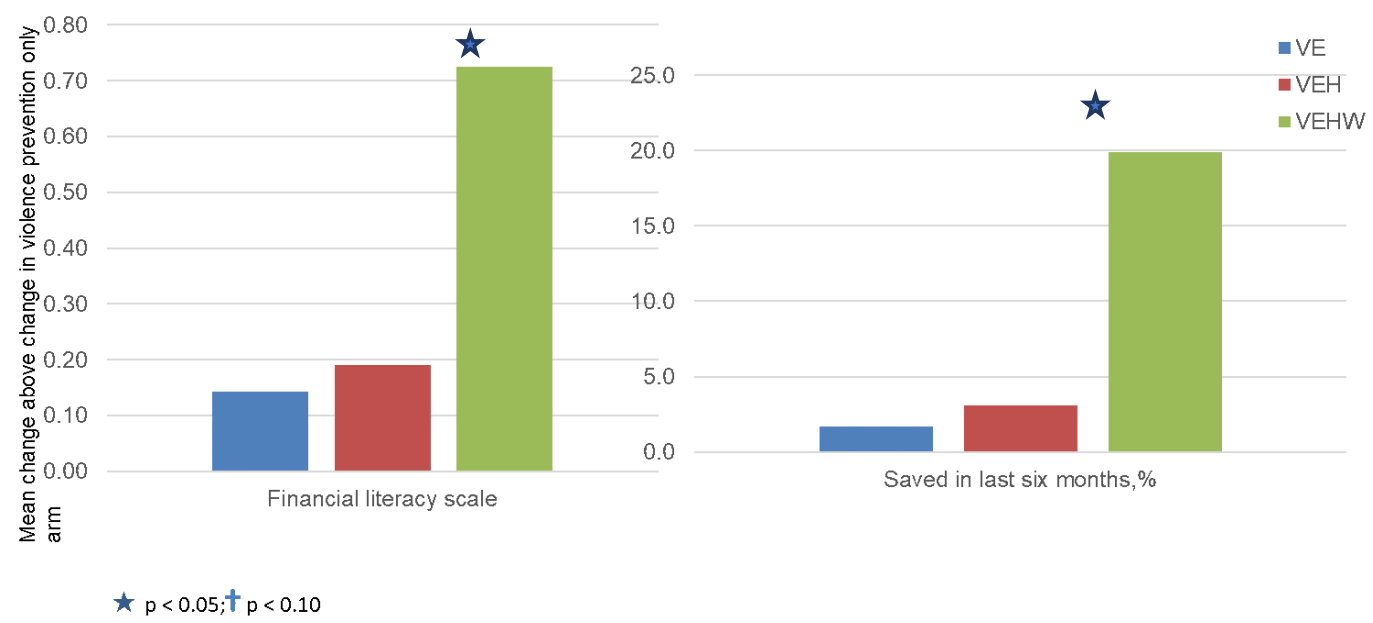

In addition, we assess whether the CCT and/or the wealth creation intervention improved the household economic status. In the household survey there were questions on if the household had KES 1,000, 5,000 and 10,000 in cash or assets that could be quickly liquidated in case of an emergency. Households that were in the CCT arms all had statistically significant increases in household liquidity relative to the V-only arm. Similarly, relative household wealth status ${ }^{23}$ among the sample shifted so that while at baseline all arms were equal, at midline the VE, VEH and VEHW arms were relatively better off as compared to the VOnly arm, with no significant difference between the three CCT arms, indicating that the CCT (and not the wealth creation intervention) had a positive effect not only on girls' education outcomes, but also the household economic status.

\section{Violence Prevention}

Overall, as girls aged from 11-15 to 13-17, experience of emotional, physical, and sexual violence in the past year increased. This is the expected trend as girls grow older. However, the increase for girls in the Vonly arm was greater than the increase for girls in the other three intervention arms. All combined, about $30 \%$ of girls in the sample had experience any kind of violence in the previous year at baseline. At midline, that figure increased by 13 percentage points for the V-only girls, but only by $4-6 \%$ for the VE, VEH, and VEHW arms. There were no significant differences between the VE, VEH and VEHW arms.

23 The index was calculated using a mix of items that included household possessions, such as television, watch, mosquito net; ownership of livestock and agricultural land as well as the number of sleeping rooms, whether the family experienced days without food in the past month and had enough savings in case of need. The responses for each of the items were dichotomized and scores calculated using principal components analysis (PCA). The scores were then categorized into wealth quintiles (five groups). 
FIGURE 7. Estimated Effects on Experience of Violence in the Past Year - Kibera, ITT

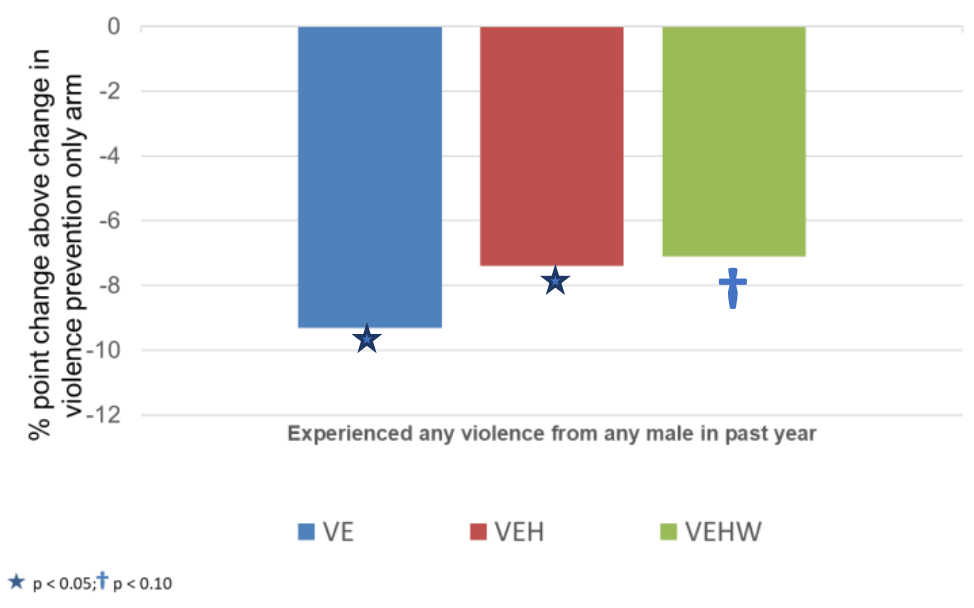

There was no impact at the household level on expectations around the timing of marriage or on gender equitable norms, although those were very high/positive at baseline so there was not a lot of room for change over the two-year intervention.

\section{WAJIR}

\section{Education}

Unlike in Kibera, the school enrollment context in Wajir at baseline was quite different. At baseline, $21 \%$ of girls had never been to school and $78 \%$ of girls were behind in their schooling relative to their age (with half being three or more years behind). Therefore, the hypothesis was that the effect of the CCT would be concentrated in school enrollment. Indeed, there were large increases in school enrollment in Wajir for girls in the CCT arms. The percent of girls who ever attended school increased by 8 to 17 percentage points above the increase that occurred in the V-only arm. In addition, the proportion of girls who attended school in the current school year (2015 at baseline and 2017 at midline) decreased by $2 \%$ in the V-only arm, compared to increases of $10 \%-20 \%$ in the CCT arms. For both measures, the improvement of the VE arm was also significantly higher than the VEH arm. Overall, $85 \%$ of the girls who were out of school at baseline and in school at midline had never been to school prior to the intervention.

In addition, there was a small but significant positive effect on numeracy skills for girls eligible for the CCT, likely driven by those girls who had entered school for the first time. While the girls who were out of school had lower learning outcome scores at midline compared to those who were in school at baseline, they made significant progress in the two years. For example, $50 \%$ of girls who were in school at baseline could correctly read two English sentences as compared to $2 \%$ of out-of-school girls. At midline, that figure increased to $79 \%$ for girls who were in school at both baseline and midline, as compared to $37 \%$ of girls who were out of school at baseline and in school at midline.

The CCT did not have an effect on primary school completion or the transition to secondary school, however that was expected as only $15 \%$ of girls were in Class 7 or 8 at baseline. There were also no effects on the self-report of missing days of school. 


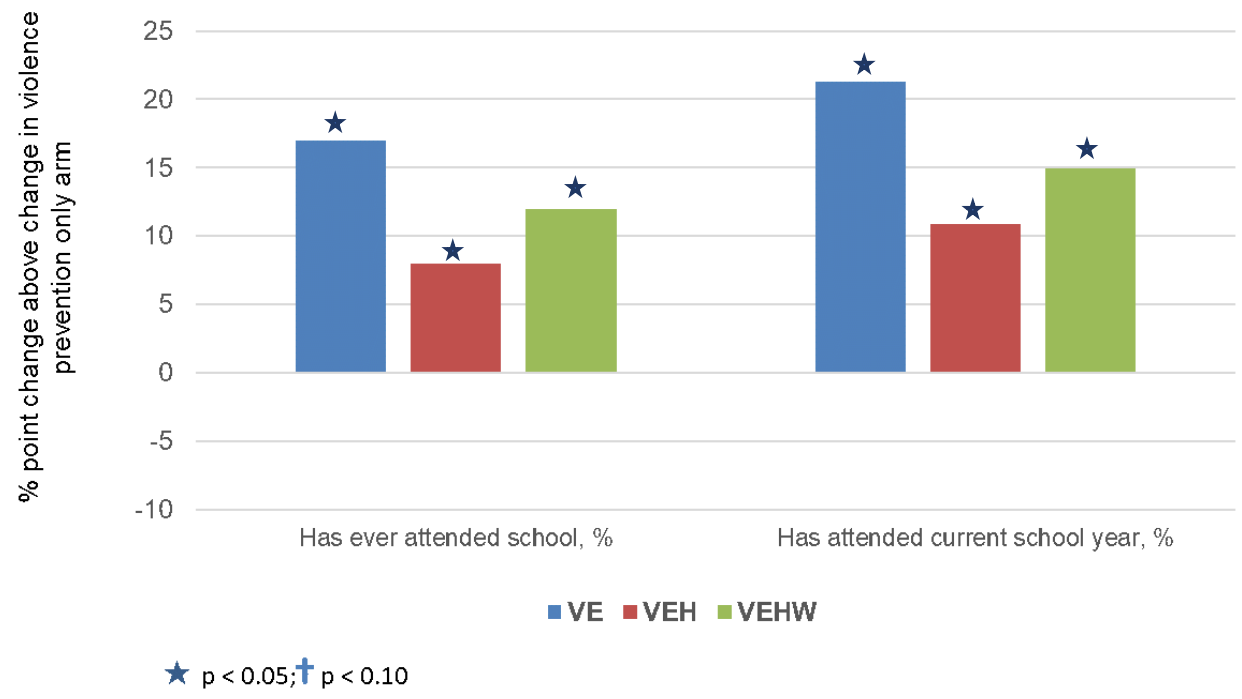

Similar to Kibera, active participation in the safe spaces groups led to larger impacts in the enrollment indicators. The effect sizes typically doubled for those girls in the TOT estimates - for example, the percentage point change above the change in the V-only arm on having attended school in the current year in the ITT was $11 \%$ and $15 \%$ for the VEH and VEHW arms, respectively, and $23 \%$ and $30 \%$, respectively in the TOT estimates. Additionally, when comparing the VEHW to the VE arms, the percent increase for the VEHW arm was significantly higher than the VE arm.

\section{Health}

In Wajir, the safe spaces intervention with the health, life-skills, and nutrition curriculum did not increase knowledge for girls in the VEH and VEHW arms on contraception, menstrual health, HIV/STIs, or nutrition. For the girls in the VEHW arm there were small but positive effects on help-seeking self-efficacy compared to the V-only and VE arms. For the girls who actively participated in the VEHW arm, there was also a positive effect on self-efficacy of about one point increased change compared to the V-only, VE, and VEH arms on a six-point scale. The effect on the help-seeking self-efficacy also doubled for those girls.

There was no change in acceptability of violence. Specifically, belief that female circumcision should continue and the intention of girls to circumcise their own daughters increased uniformly across all four arms from $75 \%$ to $89 \%$ and $77 \%$ to $88 \%$, respectively.

There was some positive change on equitable gender norms related to men's and women's roles, for example who should make decisions in a household or whether a boy's education should be prioritized over a girl's where there is a lack of resources. There was a decline in gender-equitable norms among girls in the V-only arm and increases across the VE, VEH and VEHW arms (although only the VE difference was significant). There was no significant difference between the VE, VEH, and VEHW arms, suggesting the impact was coming from the CCT.

\section{Wealth Creation}

Unlike the content of the health component of the safe spaces, the financial literacy and savings activities did have a positive impact on the girls in the VEHW arm in Wajir. The increase in financial literacy scores was 0.7 points higher on the 10-point financial literacy scale for girls in the VEHW arm, and close to double that for the VEHW girls who actively participated.

At baseline, less than $1 \%$ of girls in all arms in Wajir reported having saved. While that number only increased to $5 \%-6 \%$ for non-VEHW girls, $42 \%$ of VEHW girls reported saving in the past six months. Again, the difference in the change in the VEHW arm doubles when looking at the girls who actively participated in the VEHW safe spaces sessions, with additional change in savings behavior of 84 percentage points. 
VEHW girls also saved more, with an average cumulated savings of KES 674 as compared to KES 15 for the V-only girls. These increases in the VEHW are statistically significantly larger than the changes in the Vonly, VE and VEH arms.

FIGURE 9. Estimated Effects on Financial Literacy and Savings Behaviors - Wajir, ITT
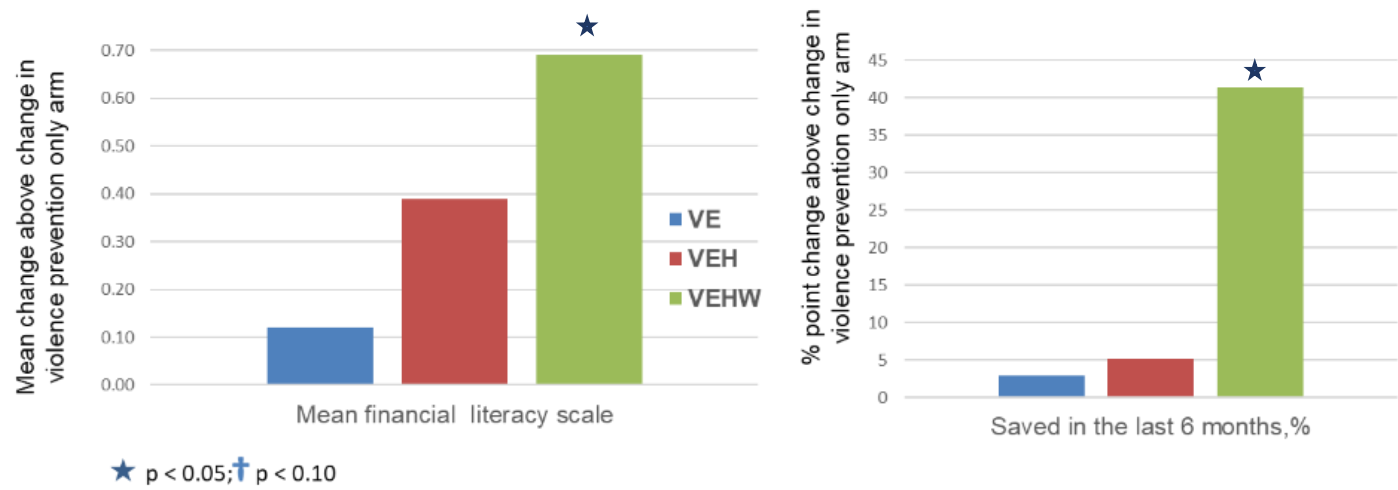

In looking at household economic status, neither the CCT nor the wealth creation intervention had an effect on the liquidity or relative wealth status of the households. In looking at the reported household expenditure data, the households were spending the cash transfer on numerous items, including food, clothes, school fees, and supplies for the AGI-K girl as well as on other children in the household and on transport, and therefore may not have been able to accumulate cash savings or household assets.

\section{Violence}

It appears that violence is significantly underreported as only 3.3\% of girls at baseline and 3.6\% of girls at midline reported experiencing violence in the past one year. Validation meetings with local stakeholders in Wajir confirm that this is grossly underreported, likely because of significant taboos around disclosing and discussing violence. Therefore, even if the program did have an effect on the experience of violence, it is impossible to detect. As such, the study data did not show that the intervention was able to reduce the experience of emotional, physical, or sexual violence among girls.

Household-level norms around expectations of girls' education improved for those households in the VE, $\mathrm{VEH}$, and VEHW arms. While there was no change in the percent of households in the V-only arm that expected that the girl would complete secondary school, there was an increase of about $10 \%$ for the other arms. Norms on the timing of marriage also slightly improved for girls eligible to participate in safe spaces groups, with the percent of households that expect the girl to marry prior to the age of 18 dropping 3\% more than the change in both the V-only and VE arms, suggesting that it was an effect of the safe spaces intervention. However, it should be noted that less than $5 \%$ of households reported expecting their daughters to marry prior to age 18 , perhaps reflecting social desirability bias.

At midline, there was no effect on the timing of marriage, however this was expected as the sample is young and only $4 \%$ of girls overall reported being married.

\section{INTERVENTION COSTS}

The incremental cost of layering on each intervention component, as well as the cost of the total intervention package per beneficiary are presented below in Table 10. 
FIGURE 10. Incremental and Intervention Annual Package Costs

\begin{tabular}{|c|c|c|c|c|}
\hline & \multicolumn{2}{|c|}{ Mbera } & \multicolumn{2}{|c|}{ Majir } \\
\hline & $\begin{array}{l}\text { Incremental } \\
\text { Annual Cost } \\
\text { (per beneficiary) }\end{array}$ & $\begin{array}{l}\text { Total Package } \\
\text { Annual Cost } \\
\text { (per beneficiary) }\end{array}$ & $\begin{array}{l}\text { Incremental } \\
\text { Annual Cost } \\
\text { (per beneficiary) }\end{array}$ & $\begin{array}{c}\text { Total Package } \\
\text { Annual Cost } \\
\text { (per beneficiary) }\end{array}$ \\
\hline $\begin{array}{l}\text { Violence } \\
\text { Prevention } \\
\text { Only }\end{array}$ & $\$ 33$ & $\$ 33$ & $\$ 116$ & $\$ 115$ \\
\hline V + Education & $\$ 242$ & $\$ 275$ & $\$ 215$ & $\$ 332$ \\
\hline$V+E+$ Health & $\$ 98$ & $\$ 373$ & $\$ 250$ & $\$ 581$ \\
\hline $\begin{array}{l}\mathrm{V}+\mathrm{E}+\mathrm{H}+ \\
\text { Wealth } \\
\text { Creation }\end{array}$ & $\$ 39$ & $\$ 412$ & $\$ 115$ & $\$ 695$ \\
\hline
\end{tabular}

Overall, we see that the interventions were more expensive to implement in Wajir, largely as a result of the challenges in working in such a vast terrain (over $30,000 \mathrm{~km}^{2}$ ) with poor infrastructure vis-à-vis roads, electricity, and security. The only intervention more expensive in Kibera was the education intervention, largely driven by the increased cost of secondary school fees, as a much larger percentage of girls in Kibera were in secondary school. In addition, the number of schools that the Kibera girls attended was much higher than in Wajir and thus required more monitoring.

The evaluation collected data on costs incurred by girls involved in the program. There are two types of costs: 1) transport costs to and from the group meetings and 2) opportunity costs of time spent in the group meetings that could have been spent on productive activities. Regarding transport costs, data from Wajir and Kibera indicated that 95\% reported spending no money to get to and from safe spaces, and that the transport time was minimal. Regarding opportunity costs, each girl spent 1.5 hours per week in the groups. First, in terms of productive time, assuming a week has 40 hours of productive time, each girl spends $4 \%$ of that time in the groups. This is not a significant amount, so we can a priori conclude that the opportunity cost is not high. Second, in terms of what they would be doing in those 1.5 hours in the counterfactual scenario, only $1 \%$ of girls reported that they would be doing paid work. To conclude, the private costs of girls participating in the program, as measured by transport and opportunity costs do not appear to be significant, based on self-reported data from the midline survey.

\section{Cost-effectiveness and economies of scope findings}

We do see that there are demonstrated economies of scope. By layering on arms, there are incremental costs, but they are lower than if one were to implement that intervention on its own. For example, safe spaces health platforms can allow further benefits to be leveraged by adding small wealth costs. However, there do not seem to be economies of scale as there are no significant fixed costs, which occur when costs decline as the number of outputs increase, when fixed costs are higher.

In order to assess cost-effectiveness, we compare unit costs per arm and incremental intervention costs to findings on program impacts. First, we look at cost-effectiveness from the perspective of the ITT analysis. When we compare the effect sizes between the arms, accounting for the added costs to adding each intervention component, the additional costs only result in additional benefit for the outcomes related to that specific intervention, but do not increase the effect size on outcomes related to other interventions. For example, adding on the wealth creation intervention improved financial literacy and savings outcomes, but did not increase the effect size on the health or education outcomes (apart from primary school completion in Kibera). However, since the objective of AGI-K was to improve outcomes across a range of adolescent well-being outcomes, as opposed to only education or only economic empowerment, the VEHW 
package presents good value for money as it makes use of economies of scope via delivery of a fourintervention package and also delivers the widest range of positive effects.

We also then use the TOT analysis, where we see that the added costs of the combined safe spaces (health + wealth) not only led to a larger effect size on the health and wealth creation outcomes, but also larger effects on education for the subset of girls who actively participated. Furthermore, the difference in impact between the VE and VEHW arms in Kibera is statistically significant. Similarly, for Wajir the effects on school enrollment were also double for girls who actively participated in the VEH and VEHW arms.

Therefore, this shows that the girls who are actively participating in empowerment activities (safe spaces) are getting more benefits from the education cash transfer, especially in Kibera. Thus, the additional costs for the safe spaces-based interventions (health and wealth creation) do result in additional benefits on key indicators for the subset of girls who actively participate, and potentially outweigh the incremental costs of safe spaces. This is particularly true if one is looking to improve girls' well-being across a range of outcomes and not only education. The bulk of the cost in the health and wealth creation interventions is the establishment and operation of the safe spaces platform; the integration of financial education and savings accounts/home banks into those groups is a small incremental cost relative to the benefit.

In summary, the value-for-money conclusion from these midline results is that a) the VEHW arm results in the widest range of positive impacts for all girls, and b) the incremental costs of health and wealth creation enhance the education benefits in addition to their own health and wealth benefits for a subset of girls who are actively participating. Therefore, delivering the four interventions as a combined package provides better value for money than undertaking any one of them on its own. This would point to the benefits of undertaking a multi-pronged approach to improving girls' welfare; i.e., if your objective is to maximize girls' welfare is it more cost-effective to undertake education alongside wealth and health interventions, as unit costs are lower, and unit benefits are higher.

We will revisit these interim conclusions during the endline analysis, when we will have data on actual outcomes related to behavior change vis-à-vis sexual behavior, timing of marriage, and childbearing.

\section{SUMMARY OF RESULTS}

The table below shows a summary of all key study indicators. Green boxes indicate a statistically significant difference in comparison to the V-only arm.

\begin{tabular}{|c|c|c|c|c|c|c|}
\hline \multirow{2}{*}{$\begin{array}{l}\text { Indicator } \\
\text { Education }\end{array}$} & \multicolumn{3}{|c|}{ Kibera } & \multicolumn{3}{|c|}{ Wajir } \\
\hline & VE & VEH & VEHW & VE & VEH & VEHW \\
\hline Ever attended school, \% & & & & $\checkmark$ & $\checkmark$ & $\checkmark$ \\
\hline Attended school in the current school year, $\%$ & & & $\checkmark$ & $\checkmark$ & $\checkmark$ & $\checkmark$ \\
\hline $\begin{array}{l}\text { Among those in class } 7 \text { and } 8 \text { at baseline: } \% \text { who } \\
\text { completed primary school }\end{array}$ & $\checkmark$ & & $\checkmark$ & & & \\
\hline $\begin{array}{l}\text { Among those in class } 7 \text { and } 8 \text { at baseline: } \% \text { who } \\
\text { transitioned to secondary school }\end{array}$ & & & $\checkmark$ & & & \\
\hline Schooling self-efficacy, mean & $\checkmark$ & & & + & & \\
\hline \multicolumn{7}{|l|}{ Literacy score, mean } \\
\hline Numeracy score, mean & & & & $\checkmark$ & $\checkmark$ & $\checkmark$ \\
\hline \multicolumn{7}{|l|}{ Health } \\
\hline Contraceptive method knowledge & & $\checkmark$ & $\checkmark$ & & & \\
\hline $\begin{array}{l}\text { Sexual and reproductive health knowledge } \\
\text { (menstruation/STIs, HIV), mean }\end{array}$ & & $\checkmark$ & $\checkmark$ & & & \\
\hline General self-efficacy, mean & & & & & & + \\
\hline Condom self-efficacy, mean & & $\checkmark$ & $\checkmark$ & & & \\
\hline Help-seeking self-efficacy, mean & & + & $\checkmark$ & & & $\checkmark$ \\
\hline Has female friend that she meets regularly, \% & $\checkmark$ & $\checkmark$ & $\checkmark$ & & & \\
\hline
\end{tabular}




\begin{tabular}{|c|c|c|c|c|c|c|}
\hline Has female adult that she meets regularly, \% & & $\checkmark$ & $\checkmark$ & & & \\
\hline \multicolumn{7}{|l|}{ Acceptability of IPV, \% } \\
\hline Gender norms, \% & & & & $\checkmark$ & & \\
\hline \multicolumn{7}{|l|}{ Wealth Creation } \\
\hline Financial literacy score, mean & & & $\checkmark$ & & & $\checkmark$ \\
\hline Savings frequency, mean & & & $\checkmark$ & & & $\checkmark$ \\
\hline Savings amount, mean & & & $\checkmark$ & & & $\sqrt{ }$ \\
\hline Household liquidity, \% & $\checkmark$ & $\checkmark$ & $\checkmark$ & & & \\
\hline Household wealth status, $\%$ & $\checkmark$ & + & $\checkmark$ & & & \\
\hline \multicolumn{7}{|l|}{ Violence Prevention } \\
\hline $\begin{array}{l}\text { Experience of physical, emotional, or sexual violence } \\
\text { by a male in the past one year, } \%\end{array}$ & $\checkmark$ & $\checkmark$ & + & & & \\
\hline If reported experience of violence, sought help, \% & & & & $\checkmark$ & $\checkmark$ & + \\
\hline Household-level norms on timing of girls' marriage, \% & & & & & $\checkmark$ & $\checkmark$ \\
\hline $\begin{array}{l}\text { Household-level norms on girls' educational } \\
\text { attainment, } \%\end{array}$ & & & & $\checkmark$ & $\checkmark$ & $\checkmark$ \\
\hline \multicolumn{7}{|l|}{\begin{tabular}{l|l}
$\checkmark$ & $=$ significant at the 0.05 level
\end{tabular}} \\
\hline \multicolumn{7}{|l|}{\begin{tabular}{l|l}
+ & $=$ significant at the 0.1 level
\end{tabular}} \\
\hline
\end{tabular}

\section{DISSEMINATION OF RESULTS}

Prior to drafting this report, preliminary results were shared with the National EAC, the Wajir and Kibera EACs, and the Plan International and Save The Children field-based implementing teams. In addition, the findings were presented one-on-one to key policymakers. Their questions and reflections, along with the evidence, helped to shape the conclusions presented here. A national-level dissemination meeting was held in July 2018 and there will be continued research uptake activities at county and national levels after that. Save the Children and Plan International have produced lessons-learned publications ${ }^{24}$ based on their implementing experiences. Given that there is a final round of data collection planned for 2019 which will provide a better understanding of the longer-term impacts of the intervention, final program and policy recommendations will be made at that time. 


\section{Conclusion}

Overall the AGI-K program had positive effects on short- and medium-term education, social, health, and economic assets, largely in line with the theory of change presented above. The endline survey, to be conducted two years after the end of the intervention, will confirm whether these changes in assets in the short to medium term will translate into longer-term change in delaying childbearing -through delaying marriage in Wajir or delaying sexual debut and/or increasing contraceptive use in Kibera. However, given that the hypothesized midterm effects have largely been achieved, with a few exceptions in particular sectors, the potential to delay childbearing remains.

\section{EDUCATION}

The effects of the conditional cash transfer were positive, but the particular area of impact was dependent on the baseline status of girls' education in each site. In Kibera, given that there was near universal primary school enrollment, as hypothesized the cash transfer was beneficial for those girls in a position to complete primary school and transition to secondary school during the course of the two-year intervention. Moving forward, narrowing the scope of the CCT for girls in urban informal settlements to those nearing the transition from primary to secondary school will be more efficient. In Wajir, given that those who were near the end of primary school at the right age for their grade level were "positive deviants," and likely to be on the path to secondary school without any extra intervention, the CCT had large positive effects on bringing out-of-school girls into school and ensuring that those who are behind in their schooling relative to their age, and thus most at risk of dropout, remained enrolled. Depending on the results of the endline, that is if induced enrollment translates into delays in marriage and childbearing, future CCTs in settings such as Wajir should target those segments of adolescents.

\section{HEALTH}

In Kibera, the safe spaces groups largely impacted the girls as expected, improving knowledge, selfefficacy and social safety nets. Even more promising is the positive impact of active participation in the safe spaces groups not only on health outcomes, but on education outcomes. This provides evidence for the "cash only v. cash plus" debate to see, when considering girls' empowerment, what in addition to cash incentives would improve outcomes. The results suggest that being an active part of a girl's empowerment club, which focus on improving health knowledge, self-efficacy, and social safety nets, goes on to further improve education outcomes. This makes the investment in the cost of establishing and maintaining the safe spaces platform good value for money.

In Wajir however, the health component of the intervention did not have the hypothesized impact. Validation meetings with key stakeholders and implementers in Wajir suggest that despite community sensitization, mentor training, audio training sessions and monitoring, the community, and specifically the mentors themselves, were not prepared to deliver the sessions on sexual and reproductive health topics with girls. The objection was not with the delivery channel - as the groups met, and the economic content did have an impact - but with the SRH-focused content. It is possible that in very socially conservative settings with little infrastructure and few economic resources, the entry path is via improvements in education, wealth creation, and infrastructure first. This is supported by the choice of action plans by the community conversation groups, as in Kibera they focused on resource centers and learning opportunities for girls, while in Wajir they focused on improvements to school infrastructure. An encouraging sign, however, is that in Wajir there were small improvements in self-efficacy and gender norms -at both the girl and household levels - perhaps suggesting that the safe spaces groups did start to create opportunities for change, but that the process through which the community will accept SRH focused content is longer than the AGI-K program. The focus on girls' education via the CCT also positively impacted individual- and household-level gender norms. 


\section{WEALTH CREATION}

The wealth creation intervention led to some of the largest and most consistent change in both sites, indicating that financial education and savings for girls are both accepted and impactful. The combination of financial education sessions with savings mechanisms and opportunities confirms the literature on financial literacy that suggests that having the opportunity to immediately put into practice the new skills helps the financial literacy training to "stick." (Miller et al. 2015; Fernandes et al. 2016). The endline survey will confirm whether the improvement in economic assets for girls in the medium term will have a longer-term influence on the timing and choices around marriage and sexual relationships.

The cost of layering the wealth creation intervention onto the safe spaces platform was relatively minimal, and the education effect sizes were greater in the VEHW arms as compared to the VEH arms, therefore, in future programs using safe spaces to deliver health content, the recommendation would be to couple the health content with financial literacy and savings opportunities. In addition, in areas where formal financial services are accessible, creating opportunities for adolescent girls to open and own their own savings accounts is important for the financial institutions in Kenya to consider.

\section{VIOLENCE PREVENTION}

Although the study design does not allow us to evaluate the impact of the community-based intervention on its own, we still believe that it is important vis-à-vis the theory of change to couple household- and girllevel interventions to address girls' empowerment with a community component. Addressing the enabling environment (Blum et al. 2012) for girls is important to allow girls and their families to leverage improvements in education, skills and knowledge and translate them into longer term change. It is possible that creating space at a community level in Wajir opened up opportunities for the positive changes in gender norms at the household level driven by the other interventions.

\section{COST-EFFECTIVENESS}

The value-for-money conclusion from the midline results is that when the objective is to maximize girls' welfare on a range of indicators, it is more cost-effective to use a multi-sectoral approach - that is, to undertake education interventions alongside wealth and health interventions - as unit costs are lower, and unit benefits for those who actively participate are higher.

The evidence emerging from the AGI-K midline survey is encouraging. It has shown that change is possible in two very different, marginalized settings in Kenya. It reinforces the point that context matters and that the pathways to asset building and empowerment vary in different settings. Future interventions targeting vulnerable girls need to take into account the setting and focus on specific segments of girls in order to maximize efficiency of spending resources - particularly on education-support programs. The evidence also reinforces the theory that addressing empowerment for adolescent girls through a multi-sectoral approach leads to a larger impact and that "cash plus," or supplementing household economic incentives with additional social, health, and asset-building for girls themselves, provides the best value for money across education, health, and economic outcomes. 


\section{Appendix A}

\section{AGI-K National External Advisory Committee}

1. Kenya Women Parliamentary Association (KEWOPA)

2. National Gender and Equality Commission

3. Gender Directorate, Ministry of Devolution and Planning

4. Department of Children's Services, Ministry of Labour, Social Security \& Services

5. Department of Policy, Partnership and EAC, Ministry of Education

6. Reproductive and Maternal Health Services, Ministry of Health

7. Department of Health, Wajir County

8. County Department/Sector of Education, Wajir County

9. Kadhi, Judicial Service Commission, Wajir County

10. Wajir County Government, Humanitarian Coordinator

11. Kenya Post Office Savings Bank (Postbank)

12. Equity Bank/Equity Group Foundation

13. Gender and Social Development, Kenya Private Sector Alliance

14. Footprints Africa Foundation

15. UNICEF Kenya

16. UN Women

17. UNFPA, Reproductive Health and Youth

18. UNESCO

19. ALDEF - Wajir Local NGO

20. WASDA - Wajir Local NGO

21. Center for Rights Education and Awareness (CREAW)

22. Girl Child Network

23. Center for the Study of Adolescence (CSA)

24. Association of Media Women in Kenya

25. Department of Community Health, University of Nairobi

\section{AGI-K Kibera External Advisory Committee}

1. Office of the MP, Kibra Constituency

2. Nairobi County Assembly

3. Department of Children's Services, District Children's Officer

4. Deputy Gender Officer - Kibera, Langata Subcounty

5. County Education Officer, Nairobi County

6. District Education Officer, Langata Subcounty

7. Public Health Officer, Langata Subcounty

8. District Health Officer, Langata Subcounty

9. Assistant District Health Officer, Langata Subcounty

10. District Commissioner, National Administration

11. Equity Bank, Kibera Branch

12. Post Bank, Kenyatta Market Branch

13. Kenya Primary School Heads Association - Langata Constituency

14. Kibera Paralegal Network

15. Carolina for Kibera

16. Undugu Society

17. Shining Hope for Communities Lea Toto

18. Kibera Informal Settlements Association

19. SAVO Foundation CBO

20. Global Communities

21. Umande Trust 
22. Concern Worldwide

23. DARAJA

24. African Network for the Prevention and Protection against Child Abuse and Neglect

25. Centre for Rights Education and Awareness

\section{AGI-K Wajir External Advisory Committee}

1. Department of Children's Services, Wajir County

2. Wajir County Government, Humanitarian Coordinator

3. County Director of Education, Wajir County

4. County Health Director, Wajir County

5. County Reproductive Health Coordinator, Wajir County

6. National Drought Management Authority, Hunger Safety Net Program, Secretariat

7. Gender and Social Services, Wajir County

8. Chairman, Court User Committee, Judicial Service Commission, Wajir County

9. Teachers Service Commission, County Director

10. Community Strategy Focal Point, Wajir County, Ministry of Health

11. County Executive Committee Member - Education, Wajir County

12. Equity Bank - Wajir Branch

13. Kenya Primary School Heads Association - Wajir

14. Kadhi, Judicial Service Commission, Wajir County

15. Council of Imam Preachers of Kenya

16. Supreme Council of Kenya Muslims

17. Wajir Paralegal Network

18. Discovery Learning Alliance

19. OXFAM

20. Islamic Relief

21. WASDA

22. ALDEF

23. Mercy Corps

24. Human Rights Watch 


\section{Appendix B: Intent-to-Treat (ITT) Estimates Tables}

Tables available online:

Austrian, Karen; Soler-Hampejsek, Erica; Maluccio, John; Mumah, Joyce; Abuya, Benta, 2018. "Adolescent Girls Initiative - Kenya (AGI-K)”, https://doi.org/10.7910/DVN/94U224, Harvard Dataverse. 


\section{Appendix C: Treatment-on-the Treated (TOT) Estimates Tables}

Tables available online:

Austrian, Karen; Soler-Hampejsek, Erica; Maluccio, John; Mumah, Joyce; Abuya, Benta, 2018. "Adolescent Girls Initiative - Kenya (AGI-K)”, https://doi.org/10.7910/DVN/94U224, Harvard Dataverse. 


\section{Appendix D: Interactions Tables}

Tables available online:

Austrian, Karen; Soler-Hampejsek, Erica; Maluccio, John; Mumah, Joyce; Abuya, Benta, 2018. "Adolescent Girls Initiative - Kenya (AGI-K)”, https://doi.org/10.7910/DVN/94U224, Harvard Dataverse. 


\section{Appendix E:}

\section{PROPENSITY SCORE MATCHING BRIEF}

\section{Overview}

The Adolescent Girls Initiative-Kenya (AGI-K) evaluation did not have a "pure" randomized control group, i.e., a randomized group receiving no program interventions (Austrian et al. 2014, 2015, 2016). In densely populated Kibera, individual-level randomization provided greater statistical power than a cluster design would have, and was logistically possible. Under this design, the added components of the education, health, and wealth interventions were excludable. However, the geographically targeted violence prevention intervention was not, as it was not possible to randomly exclude girls living there from it. Therefore, to provide an opportunity to isolate the impact of the violence prevention arm alone (or comparisons between each of the other intervention arms and no intervention), a nearby non-experimental external comparison site was also included prior to program start. ${ }^{25}$ In this area, girls did not receive any of the four program interventions. As outlined in the analysis plan, propensity-score matching on baseline indicators is used to select girls from this external comparison site to minimize risk of selection bias when estimating program impacts (Austrian et al. 2016). Such matching methods are common in the evaluation literature, and their strengths and weaknesses, including the maintained underlying assumptions, are well known (Heckman, Ichimura, and Todd 1997; Gertler et al. 2016). Crucial among these, even when difference-in-difference is possible enabling control for fixed effects, is the common trends assumption: in the absence of the intervention, the difference between the two groups is assumed to be constant over time. In other words, the areas are not "developing" or trending in a different fashion over time for non-program-related reasons. A crucial step in justifying non-experimental approaches like this, then, is to examine to the extent possible the common trends assumption. The weight of evidence from our analysis, however, is that for reasons beyond our control the common trends assumption was not valid and we therefore do not report estimated impacts on violence-related outcomes using the external comparison site.

\section{Non-experimental Study Design}

Based on its broad similarities to Kibera using national census and other secondary data (APHRC 2014), the Central division (Huruma sublocation in Huruma location and Mlango Kubwa sublocation in Mathare location) was selected as the external comparison site. Referred to here as Huruma, the area was a sufficient distance away from Kibera to mitigate contamination from AGI-K. Consistent with this, few girls from Huruma, for example, attended the same schools as AGI-K girls from Kibera. Moreover, there was no known initiative operating or planned for Huruma that aimed to address violence using the community dialogue model or other approaches. Examination of the baseline data (on the sample for which valid midline observations were also available) showed a number of significant differences (Table 1). For example when initially measured in 2015 , girls from Huruma were older, somewhat further behind in school, and living in households with fewer resources according to the wealth index developed.

\section{Propensity Score Prediction}

While these initial disparities hint at possibly invalid comparisons using Huruma as an external comparison, the benefit of matching procedures is that they can be used to better align the distributions. More specifically, we can select from Huruma a subset of girls similar on observables to the girls in Kibera undergoing the intervention. To do that, we estimated a propensity score model using 2015 baseline characteristics, predicting the probability of being exposed to the intervention, i.e., of living in Kibera. To select the conditioning set of variables, we followed Imbens (2015), first assessing the statistical and normalized differences of the average covariate values by group at baseline (Table 1). As Imbens (2015) indicates, propensity score estimation may require specification searches to ensure the baseline distribution of each covariate balances across groups after subdividing the propensity score into blocks. We assessed the baseline distributions of covariates that did not balance across groups when using a linear specification. This inspection led to the inclusion of three exponential terms and two polynomials for

25 Under cluster randomization in Wajir, it was deemed infeasible to have an external control site, as community leaders indicated it was not socially acceptable to conduct research without providing some type of direct benefit. 
a propensity score estimation that was balanced. Results from the propensity score logit model are shown in Table 2.

Including a large number of observable characteristics increases the accuracy of matches based on predicted propensity scores but may limit the number of observations within the common support area (Imbens 2015). The final conditioning set contained 15 individual- and 7 household-level characteristics, as specified in Table 1. When calculating the propensity score, the balancing property was satisfied after introducing the exponentials and polynomials as shown in Table 2, treated and matched comparison units had the same mean of observable covariates selected in six blocks of propensity scores. Figure 1 displays the respective distributions of the propensity score and common support. While we followed common practice and only included girls from Kibera with a propensity score on the common support in the matching analysis below, in practice this means excluding only 7 observations or $1.4 \%$ of the sample.

\section{Examination of Common Trends Using Placebos}

To confidently infer causality of the intervention using matching techniques, even when employing difference-in-difference techniques, assessment of common trends across the two areas is important. In the AGI-K context, the violence prevention intervention addressed community behavior and norms that from the program pathway perspective would have no, or at most minimal, effects on many of the other outcomes measured in the observational surveys, especially in the short term. Therefore, to assess the validity of the common trends assumption, we examine the estimated "effect" of the violence prevention arm only against the external comparison on outcomes where we do not expect a program impact - socalled "placebos."

To ensure robust results, we do this using both nearest neighbor and kernel matching techniques (Abadie et al. 2004, Gertler et al. 2016). Specifically, we examine the effect of the program on schooling- and economic well-being-related outcomes, two areas where there were some initial differences in the Kibera and Huruma populations. If anything, positive spillovers from the program interventions might have led to improvements in those outcomes for girls in the violence prevention-only arm in Kibera (for example if neighbor families undergoing different interventions shared resources). Results are shown in Table 3. The estimates indicate that girls in the violence prevention arm fell $0.35-0.40$ grades behind untreated girls in Huruma over the two years. There economic well-being and security also deteriorated over the period relative to matched girls in Huruma. For example, there was a relative reduction of more than one-third a standard deviation in the wealth index. Additionally, their families were 10-20 percentage points less likely to have savings or liquid assets of at least KES 1,000 and were more likely to have gone without food at least once in the previous month, though this latter finding was not robust based on the kernel estimates.

Overall, then, the estimated program effects on the placebos are negative and significant. Because this is implausible as a direct result of the AGI-K program, especially in relation to the many positive program effects described in the report, our interpretation of these findings is that the common trends assumption is not valid. Huruma, which saw no direct program interventions, experienced greater secular improvements relative to Kibera, possibly related to the different composition of the two areas as well as the feature that Huruma was below Kibera on some of these outcomes at baseline and so may have been experiencing some catchup. Despite relative proximity, different informal settlements in urban Nairobi experienced different development paths (APHRC 2014)

\section{Conclusions}

Evidence of differential trends in schooling and wealth call into question the use of matching techniques for assessing aspects of the AGI-K program using the external comparison group from Huruma. Consequently, we do not pursue this approach to examine AGI-K program effects, including for example the impact of the violence prevention-only arm. 


$(1) \quad(2) \quad(3) \quad$ (4)

\begin{tabular}{|c|c|c|c|c|}
\hline Variable & $\begin{array}{l}\text { Kibera } \\
\text { mean }\end{array}$ & $\begin{array}{c}\text { Huruma } \\
\text { mean }\end{array}$ & $\begin{array}{c}\text { T-stat } \\
\text { Difference }\end{array}$ & $\begin{array}{l}\text { Normalized } \\
\text { Difference }\end{array}$ \\
\hline \multicolumn{5}{|l|}{ Individual Characteristics } \\
\hline Age & $\begin{array}{l}12.56 \\
(1.24)\end{array}$ & $\begin{array}{l}12.75 \\
(1.36)\end{array}$ & -2.37 & -0.14 \\
\hline Muslim & 0.12 & 0.30 & -7.52 & -0.44 \\
\hline Experience any type of violence in past year & 0.29 & 0.24 & 1.89 & 0.12 \\
\hline Grade for age & $\begin{array}{l}-0.84 \\
(1.19)\end{array}$ & $\begin{array}{l}-1.29 \\
(1.37)\end{array}$ & 5.77 & 0.35 \\
\hline Currently attend school & 0.99 & 0.97 & 2.56 & 0.15 \\
\hline Literacy: Read all sentences Swahili and English & $\begin{array}{c}0.92 \\
(0.27)\end{array}$ & $\begin{array}{c}0.89 \\
(0.31)\end{array}$ & 1.85 & 0.11 \\
\hline Math standardized score & 0.02 & -0.01 & 0.47 & 0.03 \\
\hline Cognitive test & 0.57 & 0.57 & -0.04 & -0.00 \\
\hline HIV knowledge score & $\begin{array}{c}7.91 \\
(2.56)\end{array}$ & $\begin{array}{c}7.00 \\
(3.01)\end{array}$ & 5.30 & 0.32 \\
\hline Self-efficacy score & $\begin{array}{c}3.82 \\
(1.69)\end{array}$ & $\begin{array}{c}3.98 \\
(1.74)\end{array}$ & -1.44 & -0.09 \\
\hline \multicolumn{5}{|l|}{ Has a female adult in the community to ask for } \\
\hline help & $\begin{array}{c}0.48 \\
(0.50)\end{array}$ & $\begin{array}{c}0.43 \\
(0.50)\end{array}$ & 1.69 & 0.10 \\
\hline Gender attitudes score & 0.54 & 0.51 & 1.18 & 0.07 \\
\hline Expect to get married before age 22 & 0.09 & 0.16 & -3.61 & -0.22 \\
\hline Saved any money in the previous 6 months & 0.28 & 0.29 & -0.51 & -0.03 \\
\hline Financial literacy score & $\begin{array}{c}5.78 \\
(1.86)\end{array}$ & $\begin{array}{c}5.69 \\
(1.80)\end{array}$ & 0.83 & 0.05 \\
\hline \multicolumn{5}{|l|}{ Household Characteristics } \\
\hline Wealth Index - Principal Component 1 & $\begin{array}{c}0.27 \\
(1.71)\end{array}$ & $\begin{array}{l}-0.24 \\
(1.46)\end{array}$ & 5.18 & 0.32 \\
\hline Wealth Index - Principal Component 2 & $\begin{array}{c}0.34 \\
(1.16)\end{array}$ & $\begin{array}{l}-0.31 \\
(1.05)\end{array}$ & 9.58 & 0.57 \\
\hline Wealth Index - Principal Component 3 & $\begin{array}{c}0.04 \\
(1.11)\end{array}$ & $\begin{array}{l}-0.04 \\
(1.05)\end{array}$ & 1.14 & 0.07 \\
\hline Mother's education & $\begin{array}{c}8.11 \\
(2.47)\end{array}$ & $\begin{array}{c}7.72 \\
(2.51)\end{array}$ & 2.50 & 0.15 \\
\hline Mother lives in the household & 0.76 & 0.88 & -4.77 & -0.29 \\
\hline Mother works for pay & 0.66 & 0.60 & 2.02 & 0.12 \\
\hline Mother number of living children & $\begin{array}{c}1.06 \\
(0.28)\end{array}$ & $\begin{array}{c}1.03 \\
(0.18)\end{array}$ & 2.14 & 0.13 \\
\hline $\mathrm{N}$ & 506 & 560 & & \\
\hline
\end{tabular}

Notes. Standard deviations in parentheses. Column (3) reports t-stats for the test of mean differences between Kibera (treatment) and Huruma (comparison) prior to matching. 
TABLE 2. Propensity Score Estimation

\begin{tabular}{|c|c|}
\hline & Treated (Kibera) \\
\hline \multicolumn{2}{|l|}{ Individual Characteristics } \\
\hline \multicolumn{2}{|l|}{ Age } \\
\hline \multirow{2}{*}{11 years old } & $0.872 *$ \\
\hline & $(0.503)$ \\
\hline \multirow[t]{2}{*}{12 years old } & 0.728 \\
\hline & $(0.500)$ \\
\hline \multirow[t]{2}{*}{13 years old } & 0.617 \\
\hline & $(0.511)$ \\
\hline \multirow[t]{2}{*}{14 years old } & $0.918 *$ \\
\hline & $(0.522)$ \\
\hline \multirow[t]{2}{*}{15 years old } & 0.168 \\
\hline & $(0.571)$ \\
\hline \multirow[t]{2}{*}{16 years old } & 0.050 \\
\hline & $(1.006)$ \\
\hline \multirow[t]{2}{*}{ Muslim } & $-0.598 * * *$ \\
\hline & $(0.194)$ \\
\hline \multicolumn{2}{|l|}{ Exponential: Experienced any type of violence in the previous } \\
\hline \multirow{2}{*}{ year } & 0.023 \\
\hline & $(0.093)$ \\
\hline \multirow[t]{2}{*}{ Grades for each } & $0.283 * * *$ \\
\hline & $(0.073)$ \\
\hline \multirow[t]{2}{*}{ Currently attend school } & 1.187 \\
\hline & $(0.748)$ \\
\hline \multirow[t]{2}{*}{ Exponential: Literacy: Read all sentences Swahili and English } & -0.079 \\
\hline & $(0.154)$ \\
\hline \multirow[t]{2}{*}{ Exponential: Math standardized score } & -0.057 \\
\hline & $(0.122)$ \\
\hline \multirow[t]{2}{*}{ Cognitive test score } & 2.630 \\
\hline & $(2.417)$ \\
\hline \multirow[t]{2}{*}{ Cognitive test score squared } & -3.107 \\
\hline & $(2.164)$ \\
\hline \multirow[t]{2}{*}{ HIV knowledge score } & $0.080 * * *$ \\
\hline & $(0.028)$ \\
\hline \multirow[t]{2}{*}{ Self-efficacy score } & -0.054 \\
\hline & $(0.043)$ \\
\hline \multirow[t]{2}{*}{ Has a female adult in the community to ask for help } & 0.110 \\
\hline & $(0.145)$ \\
\hline \multirow[t]{2}{*}{ Gender attitudes score } & -0.065 \\
\hline & $(0.145)$ \\
\hline \multirow[t]{2}{*}{ Expect to get married before age 22} & $-0.604 * * *$ \\
\hline & $(0.222)$ \\
\hline Saved any money in the previous 6 months & -0.227 \\
\hline & $(0.159)$ \\
\hline Financial literacy score & 0.033 \\
\hline & $(0.042)$ \\
\hline Household Characteristics & \\
\hline Wealth Index - Principal Component 1 & $0.209 * * *$ \\
\hline & $(0.052)$ \\
\hline Wealth Index - Principal Component 1 squared & -0.017 \\
\hline & $(0.022)$ \\
\hline Wealth Index - Principal Component 2 & $0.465 * * *$ \\
\hline & $(0.068)$ \\
\hline
\end{tabular}


Mother lives in the household

Mother works for pay

Mother's number of living children

Constant

$\mathrm{N}$

1,054

Notes. Logit. Standard errors in parentheses. ${ }^{*} p<0.10,{ }^{*} p<0.05,{ }^{* *} p<0.01$. In cases where mother's level of education or number of children was missing, the respective median value per group was imputed, retaining those observations for the propensity score estimation. 


(1) (2) (3) (4)

\begin{tabular}{lcccc} 
& Grades ahead & Wealth index & $\begin{array}{c}\text { Enough savings } \\
1,000\end{array}$ & $\begin{array}{c}\text { Gone without } \\
\text { food }\end{array}$ \\
\hline Nearest neighbor & $-0.345 * * *$ & $-0.381 * * *$ & $-0.128 * * *$ & $0.141 * * *$ \\
Kernel & $(0.045)$ & $(0.099)$ & $(0.035)$ & $(0.034)$ \\
& $-0.400 * * *$ & $-0.766 * * *$ & $-0.201 * * *$ & 0.017 \\
& $(0.045)$ & $(0.105)$ & $(0.042)$ & $(0.038)$ \\
Observations & & & & \\
Baseline mean (Huruma) & 1,036 & 1,048 & 1,054 & 1,054 \\
Midline mean (Huruma) & -1.288 & -0.172 & 0.495 & 0.373 \\
Baseline mean (Kibera) & -1.357 & 0.185 & 0.580 & 0.402 \\
Midline mean (Kibera) & -0.820 & 0.190 & 0.577 & 0.541 \\
\hline \hline
\end{tabular}

Notes. Nearest neighbor estimations with five neighbors and exact matching on age. Heteroskedastic robust standard errors in parentheses based on two neighbors. Kernel with bandwidth 0.06 and 500 bootstrapping repetitions for calculation of standard errors. All models include the baseline measure of the outcome as a control.

FIGURE 1. Distribution of Propensity Scores for Treatment and Non-Experimental Comparison Samples

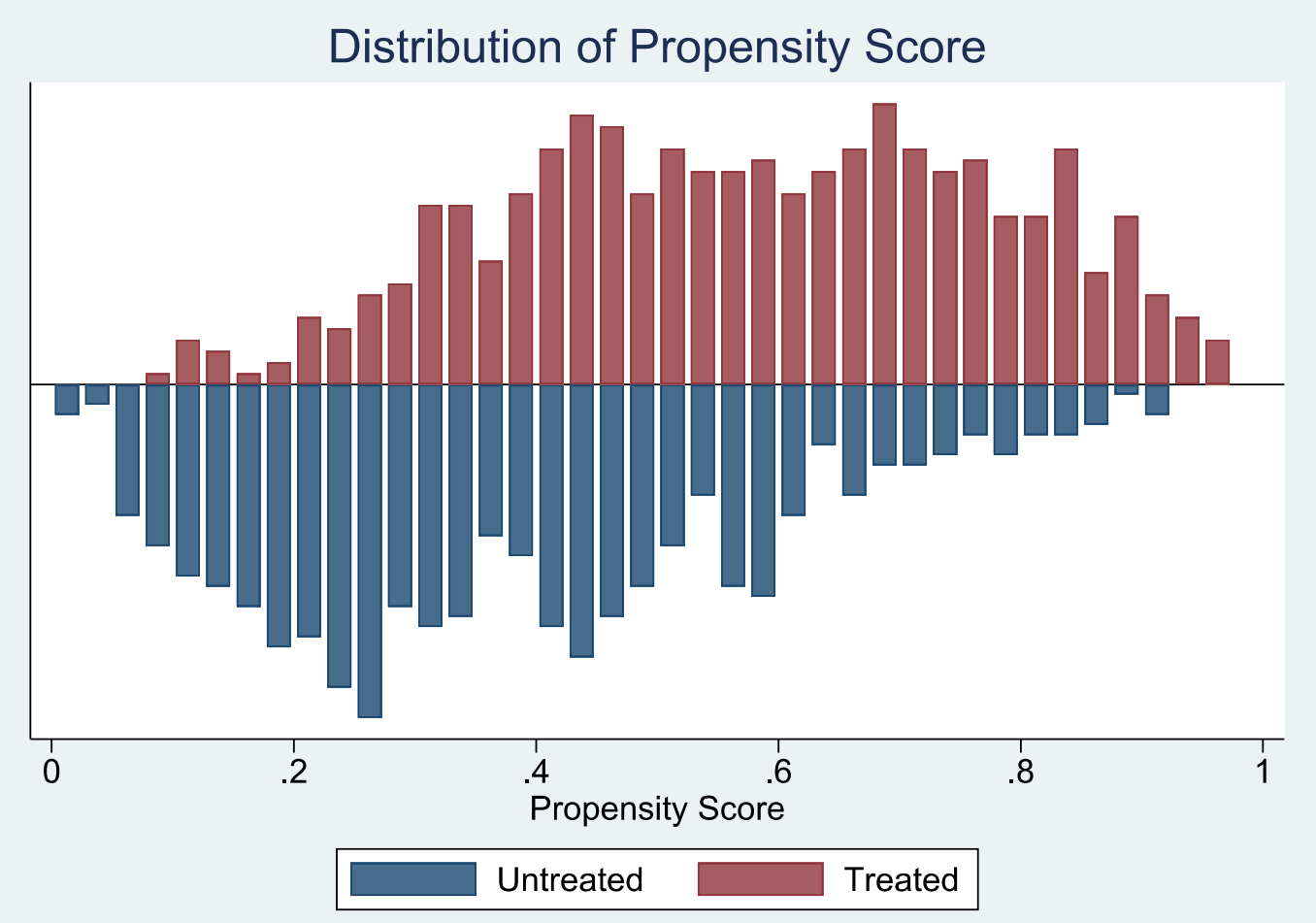




\section{References}

Abadie, Alberto et al. 2004. "Implementing matching estimators for average treatment effects in Stata," Stata Journal(4): 290-311.

African Population and Health Research Center (APHRC). 2014. Nairobi Cross Sectional Slum Survey (NCSS) II: Report on Demographic Behavior, Health Outcomes and Livelihoods Conditions of the Urban Poor in Nairobi Informal Settlements [Unpublished Report]. Nairobi: APHRC.

Austrian, K. and D. Ghati. 2010. Girl-Centered Program Design: A Toolkit to Develop, Strengthen and Expand Adolescent Girls Programs. Nairobi: Population Council.

Austrian, K. and E. Muthengi. 2014. The Adolescent Girls Initiative-Kenya (AGI-K): Intervention and Research Design Report. Nairobi: Population Council.

Austrian, K., E. Muthengi, T. Riley, J. Mumah, C. Kabiru, and B. Abuya. 2015. The Adolescent Girls Initiative-Kenya (AGI-K) Baseline Report. Nairobi: Population Council.

Austrian, K., E. Muthengi, J. Mumah, E. Soler-Hampejsek, C. Kabiru, B. Abuya, and J.A. Maluccio. 2016. "The Adolescent Girls Initiative-Kenya (AGI-K): Study Protocol," BMC Public Health (16): 210.

Blum, R.W., F.I. Bastos, C.W. Kabiru, and L.C. Le. 2012. "Adolescent health in the 21st century," The Lancet 379(9826): 1567-1568.

Bruce, J. and J. Sebstad. 2005. "Building assets for safe and productive lives: A report on a workshop on adolescent girls' livelihoods." Presented at Adolescent Girls Livelihoods Meeting, New York, April 7-8, 2004. Population Council.

Fernandes D., J.G. Lynch Jr, and R.G. Netemeyer. 2016. "Financial literacy, financial education, and downstream financial behaviors," Management Science 60(8): 1861-1883.

Gertler, Paul J. et al. 2016. Impact Evaluation in Practice, Second Edition. Washington, DC: The World Bank.

Heckman, James, Hidehiko Ichimura, and Petra Todd. 1997. "Matching as an econometric evaluation estimator: Evidence from evaluating a job training programme," Review of Economic Studies 64(4): 605-654.

Imbens, Guido W. 2015. “Matching methods in practice: Three examples," Journal of Human Resources 50(2): 373-419.

Kenya National Bureau of Statistics and ICF Macro. 2015. Kenya Demographic Health Survey 2013-14. Calverton, MD: KNBS and ICF Macro.

Miller, M., J. Reichelstein, C. Salas, and B. Zia. 2015. "Can you help someone become financially capable? A meta-analysis of the literature," The World Bank Research Observer 30(2): 220-246. 
